ARTICLE

https://doi.org/10.1038/s41467-021-22982-8

\title{
Sugar transporters enable a leaf beetle to accumulate plant defense compounds
}

\author{
Zhi-Ling Yang (1) 1, Hussam Hassan Nour-Eldin (10 ${ }^{2}$, Sabine Hänniger (1) ${ }^{3}$, Michael Reichelt (1) ${ }^{4}$, \\ Christoph Crocoll (10) ${ }^{2}$, Fabian Seitz ${ }^{1}$, Heiko Vogel (i) ${ }^{3} \&$ Franziska Beran (10) ${ }^{1 凶}$
}

Many herbivorous insects selectively accumulate plant toxins for defense against predators; however, little is known about the transport processes that enable insects to absorb and store defense compounds in the body. Here, we investigate how a specialist herbivore, the horseradish flea beetle, accumulates glucosinolate defense compounds from Brassicaceae in the hemolymph. Using phylogenetic analyses of coleopteran major facilitator superfamily transporters, we identify a clade of glucosinolate-specific transporters ( $P a G T R s$ ) belonging to the sugar porter family. PaGTRs are predominantly expressed in the excretory system, the Malpighian tubules. Silencing of PaGTRs leads to elevated glucosinolate excretion, significantly reducing the levels of sequestered glucosinolates in beetles. This suggests that PaGTRs reabsorb glucosinolates from the Malpighian tubule lumen to prevent their loss by excretion. Ramsay assays corroborated the selective retention of glucosinolates by Malpighian tubules of $P$. armoraciae in situ. Thus, the selective accumulation of plant defense compounds in herbivorous insects can depend on the ability to prevent excretion.

\footnotetext{
${ }^{1}$ Research Group Sequestration and Detoxification in Insects, Max Planck Institute for Chemical Ecology, Jena, Germany. ${ }^{2}$ Department of Plant and Environmental Sciences, Faculty of Science, DynaMo Center, University of Copenhagen, Frederiksberg, Denmark. ${ }^{3}$ Department of Entomology, Max Planck Institute for Chemical Ecology, Jena, Germany. ${ }^{4}$ Department of Biochemistry, Max Planck Institute for Chemical Ecology, Jena, Germany.

凶email: fberan@ice.mpg.de
} 
hysiological and chemosensory adaptations of herbivorous insects to plant defense compounds have played an important role in the evolution of insect-plant interactions and insect host range ${ }^{1-4}$. Among the most remarkable insect adaptations is the ability to selectively accumulate (sequester) plant defense compounds for protection against generalist predators $^{5-7}$. Indeed, it is increasingly recognized that predator pressure has promoted insect adaptations to plant defenses and driven the evolution of specialized host plant associations ${ }^{7-10}$. Sequestration evolved in all major clades of herbivorous insects and is particularly widespread in the megadiverse phytophagous Coleoptera and Lepidoptera ${ }^{11}$; however, the mechanisms by which sequestering insects can accumulate ingested plant defense compounds in their body remain poorly understood.

Glucosinolates are hydrophilic defense compounds produced by plants of the order Brassicales that, together with the plant $\beta$ thioglucosidase enzyme myrosinase, constitute an activated twocomponent defense system ${ }^{12-14}$. When tissue damage brings both components together, glucosinolates are rapidly hydrolyzed to unstable aglucones that give rise to different products ${ }^{15}$, of which isothiocyanates are the most detrimental to small herbivores ${ }^{16-19}$. Some insects can prevent glucosinolate hydrolysis and accumulate ingested glucosinolates in the body ${ }^{20-25}$. A defensive function of glucosinolate sequestration has been demonstrated in specialist aphids and flea beetles, which convergently evolved insect myrosinases enabling glucosinolate activation in response to predator $\operatorname{attack}^{21,23,26}$. The turnip sawfly, Athalia rosae, sequesters glucosinolates but does not possess its own myrosinase activity, making a role in defense less likely ${ }^{27,28}$. Instead, a rapid absorption of ingested glucosinolates across the gut epithelium was proposed to constitute a detoxification mechanism as it spatially separates glucosinolates from the co-ingested plant myrosinase in the gut lumen $^{28,29}$. Due to their physicochemical properties, transport of glucosinolates and other plant glucosides such as cyanogenic and phenolic glucosides is proposed to be mediated by membrane carriers $6,23,29$. For example, Strauss et al. ${ }^{30}$ demonstrated the role of an ATP-binding cassette (ABC) transporter in the sequestration of the phenolic glucoside salicin in the defense glands of the poplar leaf beetle, Chrysomela populi. More recently, Kowalski et al. ${ }^{31}$ identified an ABC transporter in the dogbane leaf beetle, Chrysochus auratus, with high activity towards a plant cardenolide, which adult beetles sequester in defense glands. Apart from these examples, no other membrane transporters involved in sequestration have been identified to date.

We previously investigated the sequestration of glucosinolates in the flea beetle Phyllotreta armoraciae ${ }^{25,26}$. This species is monophagous on horseradish in nature, but feeds on various brassicaceous plants in the laboratory ${ }^{32-34}$ and sequesters glucosinolates mainly in the hemolymph ${ }^{25}$. Phyllotreta armoraciae prefers to sequester aliphatic glucosinolates over indolic glucosinolates; however, the sequestration pattern depends both on the levels and composition of glucosinolates in the food plant. Interestingly, the beetles also selectively excrete sequestered glucosinolates to balance the accumulation of new glucosinolates and maintain stable glucosinolate levels $\sim 35 \mathrm{nmol} / \mathrm{mg}$ beetle fresh weight $^{25}$. Based on these findings, we hypothesize that glucosinolate transporters (GTRs) are localized in the gut and Malpighian tubule epithelial membranes in $P$. armoraciae.

Here, we use a comparative phylogenetic approach to identify candidate GTR genes in the major facilitator superfamily (MFS). We focus on a $P$. armoraciae-specific clade comprising 21 putative sugar porters, which are predominantly expressed in the Malpighian tubules, and demonstrate glucosinolate-specific import activity for 13 transporters. We investigate the role of the identified GTRs in vivo using RNA interference and establish the transport mechanism of one transporter selected as a model in vitro. Our results suggest that transporter-mediated reabsorption of glucosinolates in the Malpighian tubules enables $P$. armoraciae to sequester high amounts of glucosinolates in the hemolymph.

\section{Results}

Selection of candidate transporters. To elucidate the molecular basis of GTR in P. armoraciae, we generated a gut- and Malpighian tubule-specific transcriptome. In this transcriptome, we predicted a total of 1401 putative membrane transporters using the transporter automatic annotation pipeline (TransAAP) ${ }^{35}$. Of these, 353 are putative members of the MFS (Transporter Classification (TC)\# 2.A.1; Supplementary Data 1), which are known to transport a broad spectrum of substrates including sugars and amino acids across membranes 36,37 .

We selected MFS transporters as our candidates and additionally assumed that gene duplications have played a role in the evolution of GTR activity in $P$. armoraciae. To detect species-specific expansions of MFS transporters, we annotated MFS transporters in the publicly available genomes of three nonsequestering beetle species (Supplementary Data 2). By phylogenetic analysis, we identified the largest $P$. armoraciae-specific clade comprising 21 putative sugar porters (TC\# 2.A.1.1) for further study (Supplementary Data 3). Members of this clade share between 31 and 93\% amino acid sequence identity and are most similar to insect trehalose transporters.

Functional characterization of candidate transporters. We expressed the candidate transporters in High Five insect cells and screened them for glucoside import activity. In addition to glucosinolates, we tested different types of nonhost glucosides as substrates, namely iridoid, cyanogenic, and phenolic glucosides (Fig. 1a). Insect cells expressing 15 different transporters accumulated significantly higher levels of at least one tested glucoside compared to control cells. Of these, 13 transporters were specific for glucosinolates (Fig. 1b, c), hereafter referred to as $P$. armoraciae GTR ( $P a G T R) 1$ to 13 . Most PaGTRs showed broad and overlapping substrate spectra; for example, ten different $P a G T R s$ used 2-propenyl glucosinolate, the major glucosinolate in the host plant of $P$. armoraciae, as a substrate. The other two transporters mediated iridoid glucoside uptake into insect cells, whereas phenolic and cyanogenic glucosides were not used as substrates by any of the recombinant transporters (Fig. 1c and Supplementary Fig. 1).

Tissue-specific expression of PaGTRs. To determine the localization of $P a G T R$ s in $P$. armoraciae, we compared the transcript levels in foregut, midgut, hindgut, Malpighian tubules, and other tissues by quantitative PCR. All except two PaGTRs were specifically expressed in the Malpighian tubules (Fig. 1d and Supplementary Fig. 2). Along the tubule, PaGTRs were predominantly expressed in the proximal region close to the midgut-hindgut junction (Fig. 1e and Supplementary Fig. 2d). This Malpighian tubule region was previously shown to reabsorb metabolites to prevent their loss by excretion ${ }^{38-40}$.

Function of PaGTRs in vivo. The Malpighian tubules are bathed in hemolymph, the major storage site for sequestered glucosinolates in $P$. armoraciae. We analyzed the glucosinolate levels in the hemolymph and detected total concentrations of up to $106 \mathrm{mM}$ (Supplementary Table 1). Thus, the question arises what role $\mathrm{PaGTR}$-mediated glucosiolate transport in Malpighian tubules plays in the storage of glucosinolates in the hemolymph? We addressed this question by silencing PaGTR expression in adult $P$. armoraciae beetles. We selected $P a G T R 1$ as a model 
a<smiles></smiles><smiles>CC(Cl)(Cl)OCCCCCOS(=O)(=O)ON=C(Cc1ccc(O)cc1)SCl</smiles><smiles>CC(C)(C)OON=C(Cc1c[nH]c2ccccc12)SCl</smiles><smiles>OCc1ccccc1OCl</smiles><smiles>CC(C)(C#N)O[Ge]</smiles><smiles>OCC12OC1C1OC2C2C(OC3COC3)OCC12</smiles>

Catalpol b

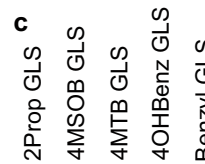

O)

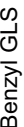

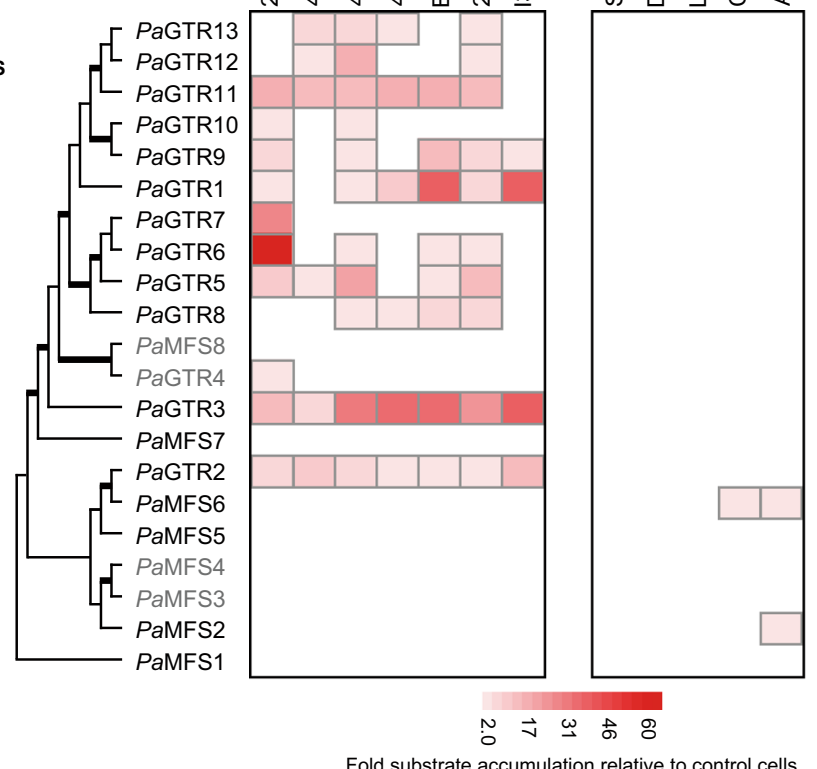

d e

e

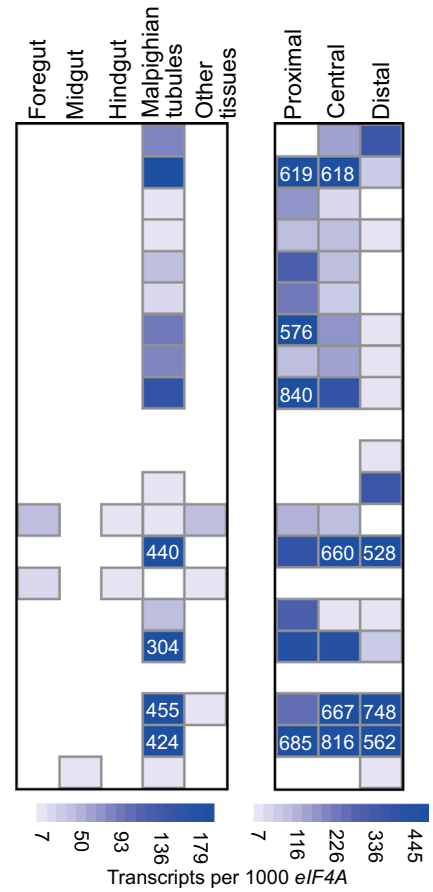

Fig. 1 Import activity and expression pattern of candidate MFS transporters. a Chemical structures of selected glucosinolates (GLS) and nonhost glucosides used in transport activity assays. b Phylogenetic relationships of candidate transporters selected based on the diversification pattern of coleopteran MFS transporters shown in Supplementary Data 3. Branches shown in bold have a bootstrap support >95\%. Recombinant proteins expressed in High Five insect cells were detected by Western blotting. For four candidates, we did not detect recombinant protein (Supplementary Fig. 1); the names of these candidates are written in gray. c Recombinant transporters were screened for glucoside uptake activity in assays using equimolar mixtures of glucosinolates or nonhost glucosides. Glucoside accumulation in transfected insect cells is expressed relative to that in mock-transfected insect cells used as background control. Values represent the mean of three assays. d Expression pattern of candidate MFS transporter genes in different tissues of P. armoraciae. e Expression pattern of candidate MFS transporter genes in different regions of the Malpighian tubule. Copy number estimates are given per 1000 copies of mRNA of the reference gene elF4A. Low gene expression levels are visualized by limiting the scale to a value of 200 and 500 in (d) and (e), respectively. The exact values are provided for genes with higher expression levels. Each value represents the mean of four and three biological replicates in

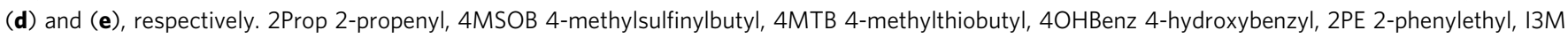
indol-3-ylmethyl.

because this transporter prefers indol-3-ylmethyl (I3M) glucosinolate, a substrate that is transported by only one other Malpighian tubule-specific transporter (Fig. 1c). After confirming the specific silencing of PaGTR1 expression by quantitative PCR (Fig. 2a and Supplementary Fig. 3a), we fed beetles with Arabidopsis thaliana Col-0 Arabidopsis) leaves containing I3M glucosinolate.

Although the treatment did not influence beetle feeding behavior (Supplementary Fig. 3b), we detected significantly less I3M glucosinolate and 1-methoxyindol-3-ylmethyl (1MOI3M) glucosinolate in PaGTR1-silenced beetles than in control beetles (Fig. 2b). In addition, PaGTR1 silencing led to elevated levels of I3M and $1 \mathrm{MOI} 3 \mathrm{M}$ glucosinolates in the feces (Fig. 2c). The levels of other glucosinolates were not reduced in PaGTR1-silenced beetles compared to the control (Supplementary Table 2 and Supplementary Fig. 4). The effect of $P a G T R 1$ knockdown on the accumulation and excretion of specific glucosinolates in $P$. armoraciae is consistent with the substrate preference of recombinant PaGTR1 in insect cell-based uptake assays, and suggests that PaGTR1 prevents excretion of two indolic glucosinolates by reabsorbing them from the Malpighian tubule lumen.

PaGTR1 is a proton-dependent high-affinity GTR. To establish the mechanism of $P a G T R 1-m e d i a t e d$ glucosinolate reabsorption, we expressed PaGTR1 in Xenopus laevis oocytes and analyzed its biochemical properties. We analyzed the substrate preference of oocyte-expressed PaGTR1 and found it to be similar to that of insect cell-expressed PaGTR1 (Fig. 2d). Previously characterized members of the sugar porter family act either as uniporters or as proton-dependent active transporters ${ }^{41-43}$; thus, we analyzed whether the extracellular $\mathrm{pH}$ influences I3M glucosinolate accumulation in PaGTR1expressing oocytes. The glucosinolate uptake rate was dependent on the external $\mathrm{pH}$ and was maximal at $\mathrm{pH}$ 6, which is consistent with the acidic $\mathrm{pH}$ in the Malpighian tubule lumen of P. armoraciae (Fig. 2e and Supplementary Fig. 5). The uptake activity decreased significantly when $\mathrm{pH}$ was $>6$, suggesting that $\mathrm{PaGTR} 1$-mediated glucosinolate transport is driven by a proton gradient across the membrane. To test this, we performed glucosinolate uptake assays at pH 6 and added either the protonophore carbonyl cyanide $m$-chlorophenyl hydrazine (CCCP), the $\mathrm{K}^{+} / \mathrm{H}^{+}$exchanger nigericin, or the $\mathrm{K}^{+}$ionophore valinomycin to the assay medium. The addition of CCCP and nigericin decreased the glucosinolate uptake rates by $77 \%$ and $50 \%$ compared to control assays, respectively, whereas valinomycin did not influence transport by $P a G T R 1-e x p r e s s i n g$ oocytes. The effects of different ionophores on glucosinolate transport show that $\mathrm{PaGTR} 1$-mediated glucosinolate uptake is proton-driven, but is not influenced by $\mathrm{K}^{+}$(Fig. $2 \mathrm{f}$ ).

A time-course analysis of $\mathrm{I} 3 \mathrm{M}$ glucosinolate accumulation in PaGTR1-expressing oocytes revealed that glucosinolate levels 


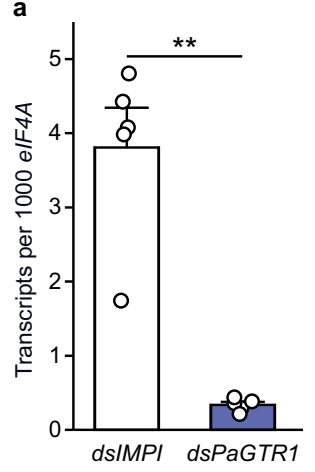

b

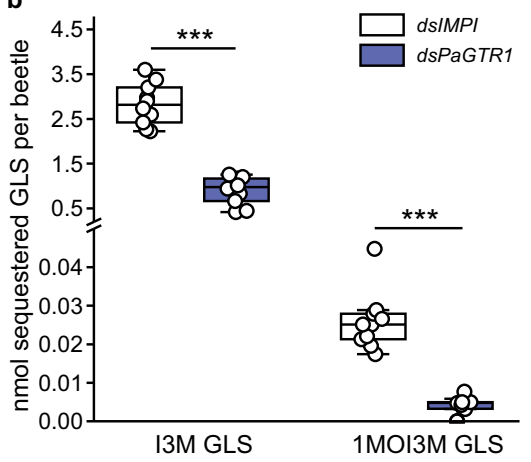

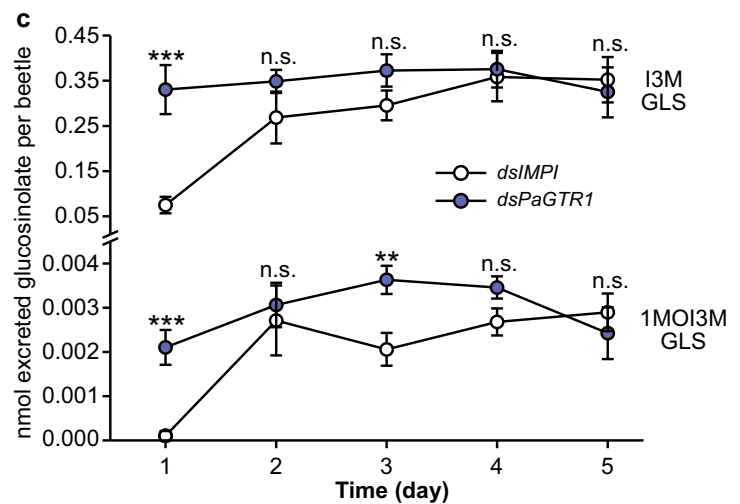

d
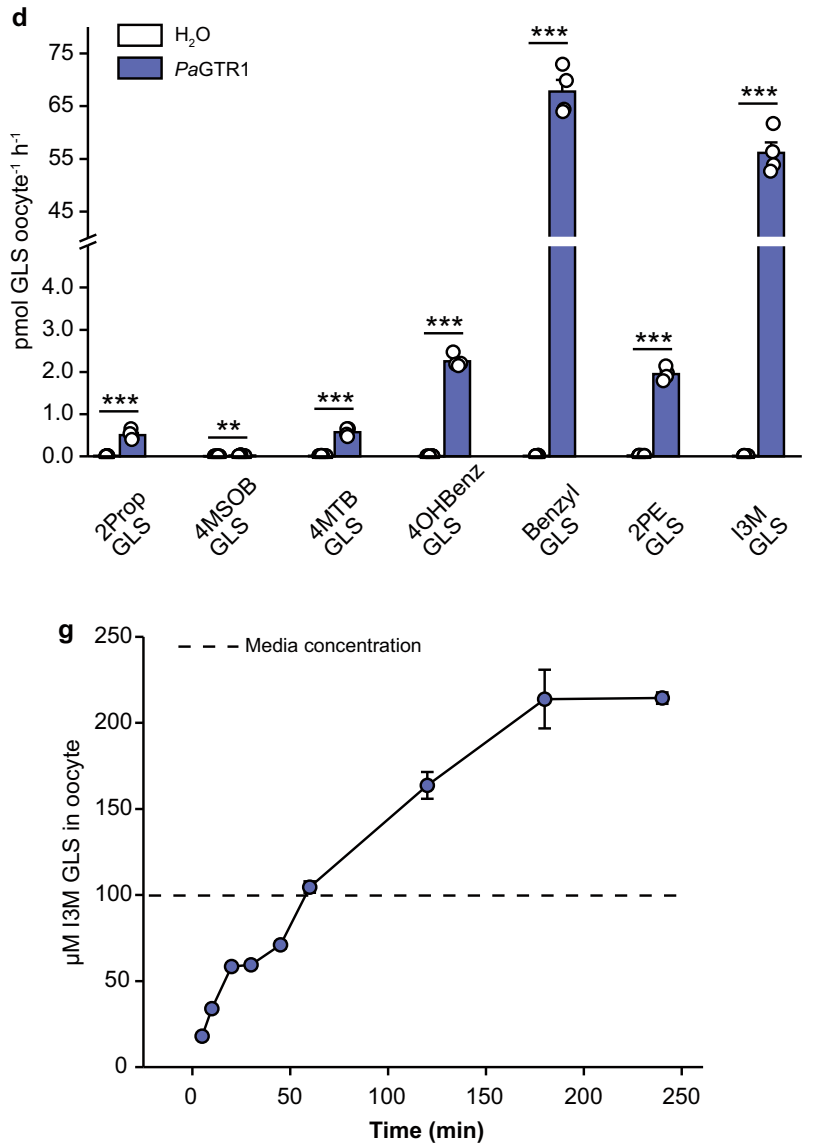

e

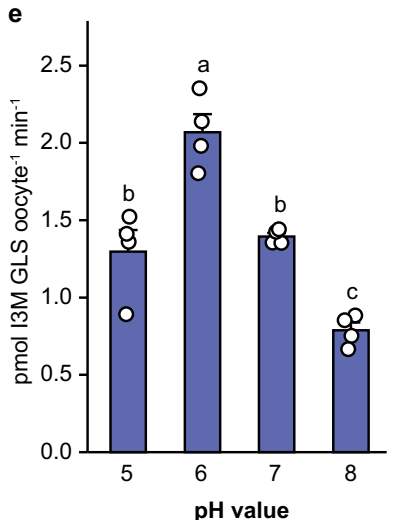

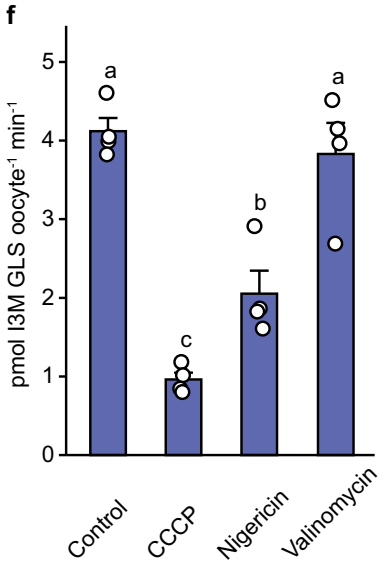

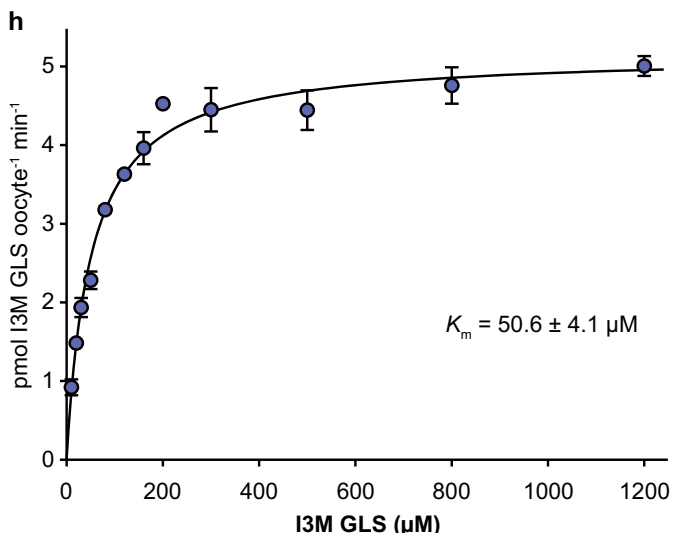

Fig. 2 Functional and biochemical characterization of PaGTR1-mediated glucosinolate transport. a PaGTR1 expression in $P$. armoraciae 4 days after dsRNA injection ( $n=5$ biological replicates, three beetles per replicate). b Accumulation of indol-3-ylmethyl (I3M) GLS and 1-methoxyindol-3-ylmethyl (1MOI3M) GLS in adult $P$. armoraciae beetles after 5 days feeding on Arabidopsis leaves. Box plots show the median, interquartile range, and outliers of each dataset ( $n=10$ biological replicates, five beetles per replicate). c Excreted amounts of I3M GLS and 1MOI3M GLS over 5 days feeding on Arabidopsis ( $n=9-10$ biological replicates, feces of five beetles per replicate). $\mathbf{d}$ Substrate preference of PaGTR1. Oocytes expressing PaGTR1 and control oocytes were incubated with equimolar mixtures of seven glucosinolates $(n=4$ biological replicates, three oocytes per replicate). e pH dependency of $P a G T R 1$ ( $n=4$ biological replicates, three oocytes per replicate). $\mathbf{f}$ Effects of different ionophores on PaGTR1-mediated glucosinolate transport ( $n=4$ biological replicates, three oocytes per replicate). $\mathbf{g}$ Time course of glucosinolate accumulation in Xenopus oocytes expressing PaGTR1 ( $n=4$ biological replicates, three oocytes per replicate). h Kinetic analysis of PaGTR1-mediated I3M GLS transport ( $n=4$ biological replicates, three oocytes per replicate). Data are shown as mean \pm s.e.m. Treatments were compared by two-tailed Student's $t$ test, Mann-Whitney $U$ test or the method of generalized least squares (a-d), or oneway analysis of variance (ANOVA). Bars labeled with different letters are significantly different $(\mathbf{e}, \mathbf{f} ; P<0.05)$. n.s. Not significantly different; ${ }^{\star \star} P<0.01$ and ${ }^{* \star *} P<0.001$. $P$ values are provided in Supplementary Data 6.

saturated after $3 \mathrm{~h}$ at an intracellular concentration that was twofold higher than in the assay buffer. This result confirmed that $P a G T R 1$ can mediate glucosinolate uptake against a concentration gradient (Fig. $2 \mathrm{~g}$ ). Plotting the transport rate as a function of increasing glucosinolate concentration yielded a saturation curve that was fitted to Michaelis-Menten kinetics with a $K_{\mathrm{m}}$ value of $50.6 \pm 4.1 \mu \mathrm{M}$ (Fig. 2h). Considering the much higher I3M glucosinolate concentration of $2082 \pm 668 \mu \mathrm{M}$ in the hemolymph (Supplementary Table 1), our results characterize PaGTR1 as a high-affinity proton-dependent GTR. 
a

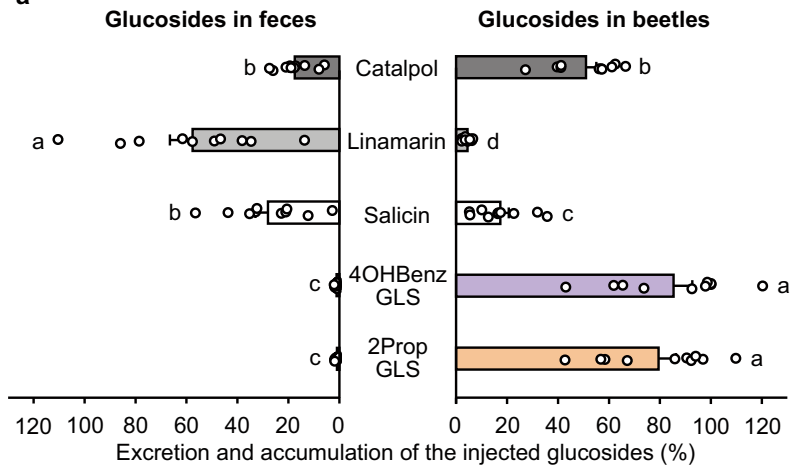

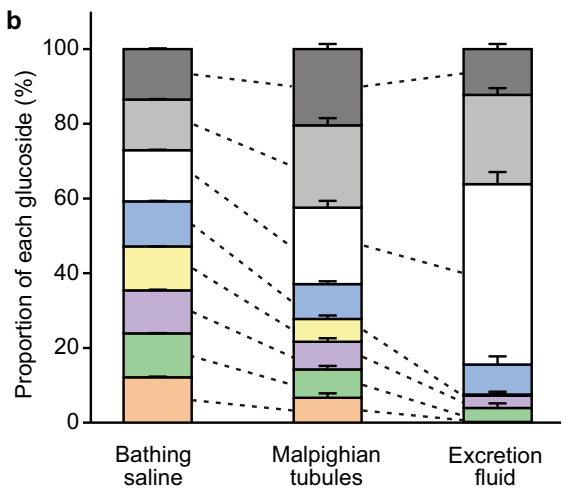

Catalpol Linamarin Salicin I3M GLS 2PE GLS 4OHBenz GLS 4MSOB GLS 2Prop GLS

Fig. 3 Selective excretion of plant glucosides in vivo and in situ. a Excretion and accumulation of plant glucosides injected in beetles. Each beetle was injected with $100 \mathrm{~nL}$ of an equimolar mixture of five glucosides. Beetles were sampled 30 min after the injection and after 1 day feeding on Arabidopsis ( $n=10$ biological replicates, five beetles per replicate). Glucoside excretion was analyzed by quantifying the amount of excreted glucosides in the feces ( $n=10$ biological replicates, feces of five beetles per replicate). Glucoside content in beetles and feces is expressed relative to the glucoside amounts detected in beetles 30 min after injection (set to 100\%). The relative accumulation and excretion of glucosides were compared using the method of generalized least squares, respectively. Bars labeled with different letters are significantly different $(P<0.05)$. b Excretion of plant glucosides by isolated Malpighian tubules (Ramsay assay). The dissected Malpighian tubule was placed in a droplet of saline and a mixture of eight different plant glucosides each at a concentration of $6.7 \mathrm{mM}$. To visualize excretion, we added $0.1 \%$ (w/v) amaranth. After 2-3 h, bathing saline, Malpighian tubule, and excretion fluid were sampled, extracted, and analyzed by LC-MS/MS. Paired two-tailed Student's $t$ tests were used to compare the relative composition of plant glucosides in bathing saline and Malpighian tubule, and Malpighian tubule and excretion fluid, respectively. Dashed lines indicate significant differences between samples (FDR-corrected $P<0.05, n=11$ biological replicates, one dissected tubule per replicate). Data are shown as mean \pm s.e.m. $P$ values are provided in Supplementary Data 6.

Phyllotreta armoraciae selectively retain glucosinolates. We further investigated the role of selective transport in Malpighian tubules by analyzing the excretion of two glucosinolates (2-propenyl- and 4-hydroxybenzyl glucosinolate) and three nonhost glucosides (salicin, linamarin, and catalpol) after injection into the hemolymph of adult $P$. armoraciae beetles. Within one day, beetles excreted between 18 and $58 \%$ of the injected nonhost glucosides and $<2 \%$ of the injected glucosinolates (Fig. 3a). In addition, we compared the recovery of injected glucosides after $30 \mathrm{~min}$ with that after 1 day. While the levels of glucosinolates remained stable, we recovered significantly less nonhost glucosides from beetle bodies. However, significantly more catalpol than salicin and linamarin was recovered (Fig. 3a), suggesting that catalpol was excreted or metabolized at a lower rate than the other two nonhost glucosides.

To confirm that the selective retention of glucosinolates in $P$. armoraciae is due to reabsorption, we analyzed glucoside excretion in situ using Ramsay assays (Supplementary Fig. 6). We exposed dissected Malpighian tubules to an equimolar mixture of glucosides and compared the glucoside composition in the bathing saline and Malpighian tubule tissue, and in the Malpighian tubule tissue and the excretion fluid, respectively. The Malpighian tubule tissue contained significantly lower proportions of glucosinolates than the bathing saline and correspondingly higher proportions of nonhost glucosides (Fig. 3b). The excretion fluid contained even lower percentages of most glucosinolates, in particular of 2-propenyl and 2-phenylethyl glucosinolates. In addition, we detected less catalpol in the excretion fluid than in the Malpighian tubule tissue. Combined, these findings show that the Malpighian tubules of $P$. armoraciae selectively reabsorb glucosinolates and catalpol, which is consistent with the substrate spectra of recombinant candidate transporters (Fig. 1c).

PaGTRs prevent the excretion of 2-propenyl glucosinolate. 2-Propenyl glucosinolate represents the major glucosinolate in the host plant of $P$. armoraciae and is sequestered at very high levels in the beetle hemolymph (Supplementary Table 1). To determine whether the identified $P a G T R$ are also capable of reabsorbing 2-propenyl glucosinolate in $P$. armoraciae, we simultaneously silenced the expression of a clade comprising four Malpighian tubule-specific transporters ( $P a G T R 5 / 6 / 7 / 8)$, among which three used 2-propenyl glucosinolate as a substrate in vitro (Fig. 1b, c). Beetles with silenced PaGTR5/6/7/8 expression excreted significantly more 2-propenyl glucosinolate than control beetles (Fig. 4a, c and Supplementary Figs. 7 and 8). In addition, 2-propenyl glucosinolate levels were significantly lower in PaGTR5/6/7/8-silenced beetles than in control beetles (Fig. 4b and Supplementary Table 3 ). These results support our hypothesis that the major function of Malpighian tubule-expressed $\mathrm{PaGTRs}$ is reabsorption.

Silencing of $\mathrm{PaGTR2}$ and $\mathrm{PaGTR} 3$ does not affect glucosinolate accumulation from Arabidopsis. Two transporter genes, $P a G T R 2$ and $P a G T R 3$, were found to be expressed in the foregut, hindgut, and other tissues. Because of their expression in the foregut, we investigated whether $P a G T R 2$ and $P a G T R 3$, which showed a broad substrate specificity in vitro, play a role in glucosinolate absorption from the gut lumen. However, silencing of $P a G T R 2$ and PaGTR3 expression did not influence the accumulation of ingested glucosinolates in beetles in feeding assays with Arabidopsis (Supplementary Fig. 9).

\section{Discussion}

In this study, we identified glucosinolate-specific transporters in $P$. armoraciae that play an important role in sequestration. We show that $P a G T R$ s are mainly expressed in the Malpighian tubules and mediate glucosinolate import in vitro. Silencing PaGTR expression in Malpighian tubules led to increased glucosinolate excretion, which indicates that $P a G T R s$ reabsorb glucosinolates from the Malpighian tubule lumen into the epithelial cells. These findings demonstrate that active reabsorption in the Malpighian tubules is required for glucosinolate accumulation in the hemolymph of $P$. armoraciae.

GTRs have previously been identified in the model plant Arabidopsis by screening 239 transport proteins for glucosinolate 

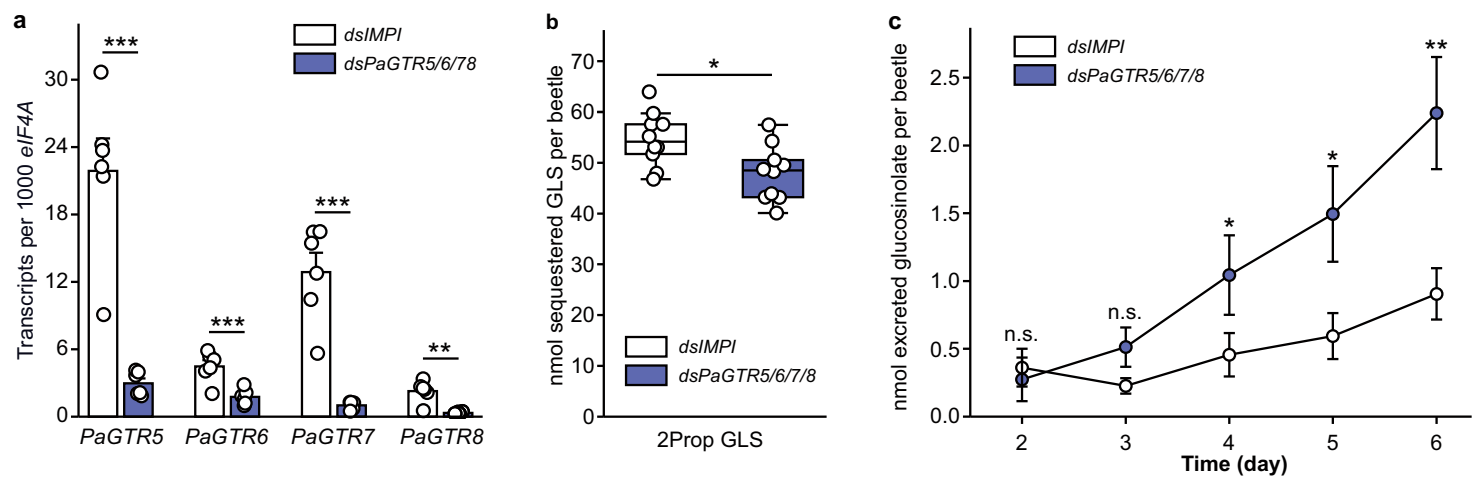

Fig. 4 In vivo functional characterization of glucosinolate transport mediated by PaGTR5/6/7/8. a PaGTR5/6/7/8 expression in P. armoraciae 6 days after dsRNA injection ( $n=6$ biological replicates, two beetles per replicate). b Accumulation of 2-propenyl glucosinolate (2Prop GLS) in adult $P$. armoraciae beetles after 6 days feeding on Arabidopsis leaves, followed by 1-day starvation. Box plots show the median, interquartile range, and outliers of each dataset ( $n=10$ biological replicates, six beetles per replicate). c Excreted amounts of 2Prop GLS from day 2 until day 6 of feeding on Arabidopsis ( $n=10$ biological replicates, feces of six beetles per replicate). Data are shown as mean \pm s.e.m. Treatments were compared by two-tailed Student's $t$ test, or Mann-Whitney $U$ test. n.s. Not significantly different; ${ }^{\star} P<0.05,{ }^{\star}{ }^{\star} P<0.01$, and ${ }^{\star \star \star} P<0.001$. $P$ values are provided in Supplementary Data 6 .

uptake activity in Xenopus oocytes ${ }^{44}$. Plant GTRs belong to the nitrate/peptide family (NPF) and presumably evolved from ancestral cyanogenic glucoside transporters ${ }^{45}$. The corresponding transporter family in $P$. armoraciae, annotated as protondependent oligopeptide transporter family, comprised only six putative transporters (Supplementary Data 1) and was not investigated in our study. Instead, our phylogenetic analysis of coleopteran MFS transporters provided evidence for speciesspecific expansions in particular within the sugar porter family, which led us to focus on the largest $P$. armoraciae-specific clade of putative sugar porters. All $\mathrm{PaGTRs}$ except for $\mathrm{PaGTR} 2$ clustered together in one well-supported group (Fig. 1b). Separate from this group, we additionally identified two iridoid glucosidespecific transporters. Our study thus highlights the potential of sugar porters to evolve activity towards glucosylated defense compounds.

The presence of iridoid glucoside-specific transporters in $P$. armoraciae was surprising, as plants of the order Brassicales do not produce iridoid glucosides ${ }^{46,47}$. Consistently, we observed reabsorption of the iridoid glucoside catalpol in Malpighian tubules (Fig. 3). Several flea beetles of the genus Longitarsus selectively sequester aucubin and catalpol ${ }^{48}$, but this genus is likely not very closely related to Phyllotreta ${ }^{49}$. Nevertheless, it is possible that iridoid glucoside-specific transporters that had evolved in an ancestor of Phyllotreta have retained their function even after flea beetles have adapted to plant families with distinct defense compounds.

An evolutionary link between the sequestration of iridoid glucosides and glucosinolates has previously been discovered in the sawfly genus Athalia in which a host shift occurred from iridoid glycoside-containing Lamiales to glucosinolate-containing Brassicacea ${ }^{50}$. Sequestration experiments demonstrated that Brassicaceae feeders were able to sequester both iridoid glucosides and glucosinolates, whereas Lamiales feeders only sequestered iridoid glucosides. Based on these findings, Opitz and co-workers hypothesized that glucoside transporters evolved a broader substrate specificity in Brassicaceae feeders. It is also imaginable that the presence of iridoid glucoside-specific transporters in the ancestor of Phyllotreta has facilitated the evolution of glucosinolate transport activity when flea beetles specialized on brassicaceous plants. To better understand the evolutionary origin of $P a G T R s$, it will be interesting to investigate the evolution and function of sugar porters across different flea beetle genera.

The specific expression of most $P a G T R$ s in the Malpighian tubules indicated an important role of the beetle's excretory system in sequestration. In fact, pioneering work by Meredith and co-workers $^{38}$ published in 1984 demonstrated that the Malpighian tubules of the large milkweed bug, Oncopeltus fasciatus, actively reabsorb the polar cardiac glycoside ouabain, which is sequestered predominantly in the integument, after its passive secretion into the Malpighian tubule lumen. Although it has generally been recognized that sequestering insects require mechanisms to prevent the excretion of polar metabolites from the hemolymph ${ }^{51}$, these mechanisms have not been further investigated. Our physiological assays demonstrate that the Malpighian tubule epithelium of $P$. armoraciae discriminates among different types of glucosinolates and nonhost glucosides and can reabsorb in particular glucosinolates against a concentration gradient (Fig. 3). Since recombinant $\mathrm{PaGTRs}$ mediated glucosinolate uptake into insect cells and Xenopus oocytes, we propose that they are located at the apical membrane and thereby enable glucosinolate reabsorption into the epithelial cells. To complete transepithelial glucosinolate transport, a so far unknown membrane transporter localized at the basolateral membrane is required to export glucosinolates into the hemolymph (Fig. 5).

The expression profile of putative sugar porter genes in P. armoraciae (Supplementary Data 2) and a recent proteomic study performed with the poplar leaf beetle C. populi $i^{52}$ showed that many sugar porters are specifically expressed in the Malpighian tubules. To our knowledge, only one Malpighian tubulespecific sugar porter has been characterized to date, i.e.sugar transporter 8 from the brown planthopper, Nilaparvata lugens, which reabsorbs trehalose ${ }^{42}$. This study provided the first evidence that sugar porters localized in Malpighian tubules can play a role in reabsorption. The localization and function of putative sugar porters we have identified in published beetle genomes have not yet been investigated; however, a phylogenetic analysis suggests that the Malpighian tubule-specific sugar porter $C p S P$-like17 from C. populi and PaGTRs evolved from a common ancestor (Supplementary Fig. 10). We thus propose that $P a$ GTRs evolved by duplications of a Malpighian tubule-localized sugar porter. Investigating the localization of flea beetle sugar porters that are phylogenetically closely related to $\mathrm{PaGTRs}$ will help to establish whether $\mathrm{PaGTRs}$ indeed evolved from Malpighian tubule-specific sugar porters.

The distinct expression pattern of PaGTR2 and PaGTR3 (Fig. 1d) suggested that $\mathrm{PaGTRs}$ are not only involved in reabsorption in the Malpighian tubules. Here, the expression in the foregut suggested, for example, a role in glucosinolate absorption. 


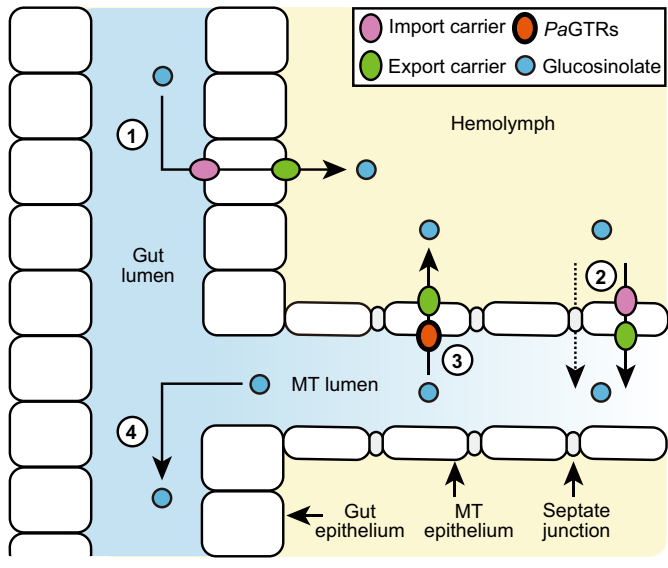

Fig. 5 Proposed model of glucosinolate sequestration in adult $\boldsymbol{P}$. armoraciae. (1) Absorption of ingested glucosinolates from the gut lumen into the hemolymph; (2) transcellular or paracellular glucosinolate transport from the hemolymph into the Malpighian tubule (MT) lumen; (3) selective reabsorption of glucosinolates from the MT lumen into the hemolymph; and (4) excretion of excess glucosinolates. PaGTRs localized in the MT are proposed to import glucosinolates from the lumen across the apical membrane into the epithelial cells.

Although the insect midgut has been proposed to be the major tissue involved in absorption ${ }^{40}$, there is initial evidence that glucosinolate absorption might already occur in the foregut of $A$. rosae larvae ${ }^{29}$. However, as silencing PaGTR2 and PaGTR3 expression had no effect on the accumulation of ingested glucosinolates in beetles, it is likely that additional or other membrane transporters are responsible for glucosinolate uptake from the gut. To establish the mechanism of glucosinolate absorption, we currently investigate the localization and specificity of glucosinolate uptake in adult $P$. armoraciae.

Transport processes play a central role in the evolution of insect sequestration mechanisms. Our study highlights that sequestering insects require mechanisms that prevent the excretion of target compounds, for example, by active reabsorption. We furthermore show that in $P$. armoraciae, reabsorption is selective and thus can control not only the level but also the composition of sequestered metabolites in the beetle. Understanding the molecular basis of sequestration now opens up the possibility to manipulate the accumulation of defense compounds in insects in order to investigate how sequestration influences trophic interactions and shapes the composition of ecological communities.

\section{Methods \\ Insect culture. Phyllotreta armoraciae beetles were reared on potted Brassica juncea cultivar "Bau Sin" plants or on potted Brassica rapa cultivar "Yo Tsai Sum" plants (Known-You Seed Co., Ltd) in mesh cages (Bugdorm, MegaView Science Co., Ltd) in a controlled environment chamber at $24^{\circ} \mathrm{C}, 60 \%$ relative humidity, and a 16 -h photoperiod. Food plants were cultivated in a growth chamber at $24^{\circ} \mathrm{C}, 55 \%$ relative humidity, and a 14 -h photoperiod. Beetles were provided with 3-4-week- old plants once per week, and plants with eggs were kept separately for larval development. Larvae were allowed to pupate in the soil, and after 3 weeks, the soil with pupae was transferred into plastic boxes ( $9 \mathrm{~L}$, Lock\&Lock) until the new generation of beetles emerged.}

RNA isolation, RNA sequencing, and de novo transcriptome assembly. Total RNA was extracted from dissected foregut, midgut, hindgut, and Malpighian tubule tissue of newly emerged $P$. armoraciae beetles that were reared on $B$. juncea using the innuPREP RNA Mini Kit (Analytik Jena). Tissues from at least ten beetles were pooled per sample. RNA integrity was verified using an Agilent Technologies 2100 Bioanalyzer with the RNA 6000 Nano Kit (Agilent Technologies). RNA quantity was determined using a Nanodrop ND-1000 spectrophotometer (PEQlab Biotechnologie $\mathrm{GmbH}$ ). One set of RNA samples was sequenced by GATC Biotech on the HiSeq 2500 System from Illumina in Rapid Run mode, using the paired-end $(2 \times 125 \mathrm{bp})$ read technology at a depth of $15-25$ million reads for each sample. For a second set of samples consisting of four biological replicates per tissue, we additionally performed an on-column DNA digestion with the innuPREP DNase I Digest Kit (Analytik Jena) according to the manufacturer's instructions. RNA samples were poly(A)-enriched, fragmented, and sequenced at the Max Planck Genome Centre Cologne on the HiSeq 3000 Sequencing System from Illumina, using the paired-end $(2 \times 150 \mathrm{bp})$ read technology at a depth of 22 million reads for each sample. Sequencing reads were filtered to remove bad-quality reads based on fastq file scores and trimmed based on read length using CLC Genomics Workbench software version 10.1. With a randomly sampled set of 420 million reads from the two sets of sequencing data, a transcriptome was assembled de novo with the following parameters: nucleotide mismatch $\operatorname{cost}=1$; insertion $=$ deletion costs $=2$; length fraction $=0.6$; similarity $=0.9$. Conflicts among the individual bases were resolved by voting for the base with the highest frequency. After removing contigs shorter than $250 \mathrm{bp}$, the final assembly contained 36,445 contigs with an N50 contig size of $2115 \mathrm{bp}$.

Identification of coleopteran MFS transporters. We predicted a protein dataset for P. armoraciae by translating each contig of the gut and Malpighian tubulespecific transcriptome into all six reading frames. After removing sequences shorter than 50 amino acids, we submitted the protein dataset $(267,568$ sequences) to the TransAAP hosted at the TransportDB 2.0 web portal ${ }^{35}$. This initial annotation predicted a total of 1401 putative transporter sequences and revealed the MFS and the $\mathrm{ABC}$ transporters to be the largest transporter families (Supplementary Data 1). We focused on MFS transporters, which are classified into $>80$ families ${ }^{53}$. We used one protein sequence from each MFS family as a query to search candidate MFS transporters in the protein dataset from $P$. armoraciae using Blastp ( $E$ value threshold of $10^{-5}$ ), and assigned each candidate to an MFS family based on sequence similarity to transporter sequences deposited in TCDB. Additional candidates were identified by repeating the search procedure with an extended dataset including the candidate MFS transporters from $P$. armoraciae. The number of TMDs for each candidate was predicted using the TMHMM Server v.2.054. Partial sequences encoding less than six predicted TMDs were removed from the dataset. The same strategy was used to identify putative MFS transporters in protein datasets that were predicted from the genomes of Leptinotarsa decemlineata, genome annotations v.0.5.3 ${ }^{55}$, Anoplophora glabripennis, assembly Agla_1. ${ }^{56}$, and Tribolium castaneum, assembly Tcas $3.0^{57}$, respectively. The predicted protein sequences are provided in Supplementary Data 2.

Digital gene expression analysis. Digital gene expression analysis of putative MFS transporters identified in the $P$. armoraciae transcriptome was carried out using CLC Genomics Workbench v.10.1 by mapping the Illumina reads from the second set of samples onto the reference transcriptome, and counting the reads to estimate gene expression levels. For the cloned MFS genes, complete open-reading frames (ORFs) were used as reference sequences for mapping. For read alignment, we used the following parameters: nucleotide mismatch cost $=2$; insertion $=$ deletion costs $=3$; length fraction $=0.6$; similarity fraction $=0.9$; maximum number of hits for a read $=15$. Each pair of reads was counted as two. Biases in the sequence datasets and different transcript sizes were corrected using the TPM (transcripts per kilobase million) normalization method to obtain correct estimates for relative expression levels between samples.

Phylogenetic analyses of coleopteran MFS transporters. We inferred the lineage-specific diversification patterns of putative MFS transporters from $P$. armoraciae, L. decemlineata, A. glabripennis, and T. castaneum in phylogenetic analyses with two different datasets, one containing all identified MFS transporters (867 sequences), the other containing a subset of putative sugar porters (120 sequences) from the above four species and 35 sugar porters from C. populi ${ }^{52}$. The corresponding protein sequences were aligned using the MUSCLE algorithm ${ }^{58}$ implemented in MEGA 7 with default parameters. The alignments were trimmed manually and the best substitution models were determined using ProtTest 3.4.259. Maximum-likelihood phylogenetic trees were constructed in IQ-TREE version 1.6.0 ${ }^{60}$ using the VT $+\mathrm{G}+\mathrm{F}$ substitution model with 1000 ultrafast bootstrap replicates for the full dataset, and the $\mathrm{LG}+\mathrm{G}+\mathrm{F}$ substitution model with 1000 bootstrap replicates for the subset of putative sugar porters.

Identification and sequencing of candidate transporters. Based on our phylogenetic analysis, we selected the largest clade of putative MFS transporters that was specifically expanded in $P$. armoraciae for further studies. Transcriptome analyses revealed the presence of a pseudogene (PaMFS9-ps) that shares between 43 and $95 \%$ nucleotide sequence identity with members of the focal clade. The protein encoded by this pseudogene is predicted to possess only two transmembrane domains due to a premature stop codon caused by frameshift mutations in the coding sequence. To obtain the full-length ORFs of partial transcripts, we synthesized $5^{\prime}$ - and $3^{\prime}$-rapid amplification of cDNA (complementary DNA) ends (RACE)-cDNA using the SMARTerRACE cDNA Amplification Kit (Clontech) and performed $5^{\prime}$ - and $3^{\prime}$-RACE-PCR according to the manufacturer's protocols 
(Clontech). All full-length ORFs were cloned into the $\mathrm{pCR}^{\mathrm{m}} 4-\mathrm{TOPO}^{\circ} \mathrm{TA}$ vector (Thermo Fisher Scientific) for sequence verification.

\section{Tissue-specific expression of candidate transporters. We used quantitative} PCR ( $\mathrm{qPCR}$ ) to analyze the expression of candidate transporter genes in the foregut, midgut, hindgut, Malpighian tubules, and other tissues of 1-day-old adult P. armoraciae beetles ( $n=4$ biological replicates, each with two technical replicates), respectively. In addition, the expression of candidate transporter genes was analyzed in the proximal, central, and distal Malpighian tubule regions (Supplementary Fig. 2d) dissected from 4 -day-old adult $P$. armoraciae beetles $(n=3$ biological replicates, each with two technical replicates). Total RNA was extracted using the InnuPrep RNA Mini Kit (Analytik Jena), treated with TURBO DNase (Thermo Fisher Scientific), and purified using the RNeasy MinElute Cleanup Kit (Qiagen). First-strand cDNA was synthesized using the Verso cDNA Synthesis Kit (Thermo Fisher Scientific) using a 3:1 mixture (v/v) of random hexamer and oligo dT primers according to the manufacturer's protocol. Quantitative PCR was performed in optical 96-well plates (Bio-Rad) on a Bio-Rad CFX Connect Real-Time System using the Absolute Blue qPCR SYBR Green Kit (Thermo Fisher Scientific). The PCR program was as follows: $95^{\circ} \mathrm{C}$ for $15 \mathrm{~min}$, then 40 cycles at $95^{\circ} \mathrm{C}$ for $15 \mathrm{~s}$, $57^{\circ} \mathrm{C}$ for $30 \mathrm{~s}$, and $72^{\circ} \mathrm{C}$ for $30 \mathrm{~s}$, followed by a melt cycle from 55 to $95^{\circ} \mathrm{C}$ in $0.5 \mathrm{~s}$ increments. Primers (Supplementary Data 4) were designed using Primer3web version 4.1.0. We verified the amplification specificity by sequencing each PCR product after cloning into the $\mathrm{PCR}^{\mathrm{m}} 4$ - $\mathrm{TOPO}^{\circ}$ TA vector (Thermo Fisher Scientific) and by melting-curve analyses. Primer efficiencies were calculated using a cDNA template dilution series. Gene expression was normalized to the expression level of eukaryotic initiation factor $4 \mathrm{~A}(e I F 4 \mathrm{~A})$, which showed the lowest variability across tissues among four tested reference genes (Supplementary Table 4).

Expression of candidate transporters in insect cells. For protein expression, we cloned each ORF without stop codon into the $\mathrm{pIEx}-4$ expression vector (Novagen) in frame with the vector-encoded carboxy-terminal $6 \times$ His-tag and sequenced the resulting constructs. Primer sequences are listed in Supplementary Data 4. One construct of each candidate gene was used for transfection of High Five $e^{\text {tw }}$ insect cells (Gibco) cultured in Express Five SFM medium (Gibco) supplemented with $20 \mathrm{mM}$ glutamine (Gibco) and $50 \mu \mathrm{g} / \mathrm{mL}$ gentamicin (Gibco). Confluent insect cells were diluted 1:5, dispensed in $500 \mu \mathrm{L}$ aliquots into 24 -well plates, and incubated at $27^{\circ} \mathrm{C}$. The next day, we transfected the cells using FuGENE HD Transfection Reagent (Promega) according to the manufacturer's protocol. Cells treated with transfection reagent only were used as a negative control. After $48 \mathrm{~h}$, we harvested the cells for Western blotting and uptake assays.

Western blotting. To confirm protein expression, transfected insect cells were washed twice with phosphate-buffered saline (PBS; pH 7.4), collected by centrifugation, and resuspended in hypotonic buffer $(20 \mathrm{mM}$ Tris- $\mathrm{HCl}$ (pH 7.5), $5 \mathrm{mM}$ EDTA, $1 \mathrm{mM}$ dithiothreitol, $0.1 \%$ benzonase nuclease (Merck Millipore) (v/v), and protease inhibitors (cOmplete Mini, ETDA-free, Roche Diagnostics $\mathrm{GmbH}$ )). After incubation on ice for $10 \mathrm{~min}$, the samples were frozen in liquid nitrogen, thawed, and centrifuged $\left(16,000 \times g\right.$ for $15 \mathrm{~min}$ at $\left.4^{\circ} \mathrm{C}\right)$. The resulting cell pellet was resuspended in hypotonic buffer and used for Western blotting using horseradish peroxidase-conjugated anti-His antibody (1:10,000; Novex, Life technologies).

Glucoside uptake assays with transfected insect cells. Cells were washed with PBS (pH 5.5) by pipetting and incubated with different glucoside substrates at 200 $\mu \mathrm{M}$ in PBS ( $\mathrm{pH}$ 5.5) for $1 \mathrm{~h}$ at $27^{\circ} \mathrm{C}$. Assays were performed with substrate mixtures containing seven different glucosinolates (2-propenyl glucosinolate (Roth), 4methylsulfinylbutyl glucosinolate (Phytoplan), 4-methylthiobutyl glucosinolate (Phytoplan), 2-phenylethyl glucosinolate (Phytoplan), benzyl glucosinolate (Phytoplan), 4-hydroxybenzyl glucosinolate (isolated from Sinapis alba seeds ${ }^{61}$ ), and I3M glucosinolate (Phytoplan)), or five other plant glucosides (salicin (SigmaAldrich), linamarin (BIOZOL), dhurrin (Roth), catalpol (Sigma-Aldrich), and aucubin (Sigma-Aldrich)). After incubation, cells were washed three times with icecold PBS (pH 5.5) by pipetting, collected in $300 \mu \mathrm{L} 80 \%$ (v/v) methanol, frozen in liquid nitrogen, thawed, and centrifuged at $3220 \times g$ for $10 \mathrm{~min}$ at $4{ }^{\circ} \mathrm{C}$. The supernatant was dried by vacuum centrifugation, dissolved in ultrapure water, and analyzed by liquid chromatography coupled with tandem mass spectrometry (LCMS/MS). All glucoside uptake assays were performed in triplicates. The amount of each substrate in transporter-expressing cells was compared with that detected in control cells. Transporters were considered active when the average glucoside amounts detected in transporter-expressing cells were at least twofold higher than those detected in control cells.

Cloning of PaGTR1 into the pNB1u vector and CRNA synthesis. We amplified the ORF of PaGTR1 without stop codon by PCR using uracil-containing primers (Supplementary Data 4 ). The $3^{\prime}$ primer was designed to encode a human influenza hemagglutinin tag to enable the detection of recombinant protein by Western blotting if necessary. The pNBlu vector was digested overnight at $37^{\circ} \mathrm{C}$ with PacI and Nt.BbvCI (New England Biolabs) to generate 8-nt overhangs. One microliter gel-purified PCR product $(100 \mathrm{ng} / \mu \mathrm{L})$ was combined with $1 \mu \mathrm{L}$ gel-purified vector $(50 \mathrm{ng} / \mu \mathrm{L}), 1 \mathrm{U}$ USER enzyme, $2 \mu \mathrm{L} 5 \times$ PCR reaction buffer and $5 \mu \mathrm{L} \mathrm{H}_{2} \mathrm{O}$, incubated at $37^{\circ} \mathrm{C}$ for $25 \mathrm{~min}$, followed by $25 \mathrm{~min}$ at room temperature. After the transformation of chemically competent $E$. coli cells, colonies containing the appropriate insert were identified by Sanger sequencing. The DNA template for complementary RNA (cRNA) synthesis was amplified by PCR from the X. laevis expression construct using pNBluf/r primers (Supplementary Data 4) and cRNA was synthesized using the mMESSAGE mMACHINE ${ }^{\text {su }}$ T7 Transcription Kit (Invitrogen) according to the manufacturer's manual.

Biochemical characterization of PaGTR1 in Xenopus oocytes. The cRNA concentration was adjusted to $800 \mathrm{ng} / \mu \mathrm{L}$ with RNase-free water for oocyte injection. Xenopus laevis oocytes (Ecocyte Bioscience) were injected with $50 \mathrm{~nL}$ containing $40 \mathrm{ng}$ cRNA or with $50 \mathrm{~nL}$ pure water as a control using a Drummond NANOJECT II (Drummond Scientific Company) or a Nanoliter 2010 Injector (World Precision Instruments)

Injected oocytes were incubated in Kulori buffer $(90 \mathrm{mM} \mathrm{NaCl}, 1 \mathrm{mM} \mathrm{KCl}, 1 \mathrm{mM}$ $\mathrm{MgCl}_{2}, 1 \mathrm{mM} \mathrm{CaCl}$, and $5 \mathrm{mM}$ 4-(2-hydroxyethyl)-1-piperazineethanesulfonic acid, $\mathrm{pH}$ 7.4) supplemented with $50 \mu \mathrm{g} / \mathrm{mL}$ gentamicin at $16^{\circ} \mathrm{C}$ for 3 days until assaying All transport assays were performed at room temperature. Injected oocytes were preincubated for $5 \mathrm{~min}$ in Kulori buffer $(90 \mathrm{mM} \mathrm{NaCl}, 1 \mathrm{mM} \mathrm{KCl}, 1 \mathrm{mM} \mathrm{MgCl}, 1 \mathrm{mM}$ $\mathrm{CaCl}_{2}$, and $5 \mathrm{mM}$ 2-(N-morpholino)ethanesulfonic acid (MES), $\mathrm{pH}$ 6.0) before they were transferred into the same buffer containing the substrate(s). To determine the substrate preference of $P a G T R 1$, we incubated oocytes in Kulori buffer (pH 6.0) containing an equimolar mixture of 2-propenyl glucosinolate, 4-methylsulfinylbutyl glucosinolate, 4-methylthiobutyl glucosinolate, 2-phenylethyl glucosinolate, benzyl glucosinolate, 4-hydroxybenzyl glucosinolate, and I3M glucosinolate, each at 200 $\mu \mathrm{M}$, for $1 \mathrm{~h}$.

The $\mathrm{pH}$ dependency of glucosinolate transport was determined by incubating the injected oocytes with $100 \mu \mathrm{M}$ I3M glucosinolate for $10 \mathrm{~min}$ in Kulori buffer adjusted to different $\mathrm{pH}$ values. The effects of different ionophores on glucosinolate transport was studied by incubating the PaGTR1-expressing oocytes in Kulori buffer at $\mathrm{pH} 6.0$ containing either $20 \mu \mathrm{M}$ carbonyl cyanide $m$-chlorophenyl hydrazone ( $\mathrm{H}^{+}$ionophore, Sigma-Aldrich), $20 \mu \mathrm{M}$ nigericin $\left(\mathrm{K}^{+} / \mathrm{H}^{+}\right.$exchanger, Abcam), or $20 \mu \mathrm{M}$ valinomycin ( $\mathrm{K}^{+}$ionophore, Abcam) for $15 \mathrm{~min}$. Afterwards, we incubated the oocytes in Kulori buffer containing $100 \mu \mathrm{M}$ I3M glucosinolate and the corresponding ionophore for $10 \mathrm{~min}$. Assays performed with oocytes incubated in Kulori buffer without any ionophore served as a control.

The time course of I3M glucosinolate uptake was analyzed by incubating oocytes with $100 \mu \mathrm{M}$ I3M glucosinolate in Kulori buffer (pH 6.0) for 5, 10, 20, 30, $45,60,120,180$, and $240 \mathrm{~min}$, respectively. The apparent $K_{\mathrm{m}}$ value of PaGTR1 for I3M glucosinolate was determined by incubating injected oocytes in Kulori buffer ( $\mathrm{pH}$ 6.0) for $10 \mathrm{~min}$ with different substrate concentrations. The $K_{\mathrm{m}}$ value was calculated by nonlinear regression analysis in SigmaPlot 14.0 (Systat Software Inc.).

Each assay consisted of 14-15 oocytes and was stopped by washing oocytes four times with Kulori buffer. Afterwards, 12 of the washed oocytes were distributed into four Eppendorf tubes, with three oocytes per tube and immediately homogenized in $100 \mu \mathrm{L}$ of $50 \%(\mathrm{v} / \mathrm{v})$ methanol. After centrifugation $(21,380 \times g$ or $16,000 \times g$ for $15 \mathrm{~min}$ ), the supernatant was incubated at $-20^{\circ} \mathrm{C}$ for at least $1 \mathrm{~h}$ to precipitate proteins, which were pelleted by centrifugation $(21,380 \times g$ or $16,000 \times g$ for $15 \mathrm{~min}$ ). Finally, $60 \mu \mathrm{L}$ sample was diluted with $120 \mu \mathrm{L}$ ultrapure water, filtered through a $0.22 \mu \mathrm{m}$ PVDF-based filter plate (Merck Millipore), and analyzed by LCMS/MS. The glucosinolate concentration in oocytes was calculated by assuming an oocyte volume of $1 \mu \mathrm{L}^{62}$.

LC-MS/MS. Glucosinolates were quantified by LC-MS/MS using an Agilent 1200 HPLC system connected to an API3200 tandem mass spectrometer (AB SCIEX). Separation was achieved on an EC 250/4.6 NUCLEODUR Sphinx RP column (250 $\mathrm{mm} \times 4.6 \mathrm{~mm}, 5 \mu \mathrm{m}$; Macherey-Nagel) using a binary solvent system consisting of $0.2 \%(\mathrm{v} / \mathrm{v})$ formic acid in water (A) and acetonitrile (B), with a flow rate of $1 \mathrm{~mL} /$ $\mathrm{min}$ at $25^{\circ} \mathrm{C}$. The elution gradient was as follows: $0-1 \mathrm{~min}, 1.5 \% \mathrm{~B} ; 1-6 \mathrm{~min}$, $1.5-5 \%$ B; 6-8 min, 5-7\% B; 8-18 min, 7-21\% B; 18-23 min, 21-29\% B; 23-23.1 min, $29-100 \%$ B; $23.1-24 \mathrm{~min}, 100 \% \mathrm{~B} ; 24-24.1 \mathrm{~min}, 100$ to $1.5 \% \mathrm{~B} ; 24.1-28 \mathrm{~min}$, $1.5 \% \mathrm{~B}$. Glucosinolates were detected in negative ionization mode. The ion spray voltage was set to $-4500 \mathrm{~V}$. Gas temperature was set to $700^{\circ} \mathrm{C}$, curtain gas to 20 psi, collision gas to 10 , nebulizing gas to $70 \mathrm{psi}$, and drying gas to 60 psi. Nonhost glucosides were quantified using an Agilent 1200 HPLC system connected to an API5000 tandem mass spectrometer (AB SCIEX). Separation was achieved on an Agilent XDB-C18 column $(5 \mathrm{~cm} \times 4.6 \mathrm{~mm}, 1.8 \mu \mathrm{m})$ using a binary solvent system consisting of $0.05 \%(\mathrm{v} / \mathrm{v})$ formic acid in water (A) and acetonitrile (B) with a flow rate of $1.1 \mathrm{~mL} / \mathrm{min}$ at $25^{\circ} \mathrm{C}$. The elution gradient was as follows: $0-0.5 \mathrm{~min}, 5 \% \mathrm{~B}$; 0.5-2.5 min, 5-31\% B; 2.5-2.52 min, 31-100\% B; 2.52-3.5 min, 100\% B; 3.5-3.51 min, 100 to $5 \% \mathrm{~B} ; 3.51-6 \mathrm{~min}, 5 \% \mathrm{~B}$. Compounds were detected in negative ionization mode with ion spray voltage set to $-4500 \mathrm{~V}$. The gas temperature was set to $700{ }^{\circ} \mathrm{C}$, curtain gas to $30 \mathrm{psi}$, collision gas to 6 , and both nebulizing gas and drying gas to $60 \mathrm{psi}$. Multiple reaction monitoring (MRM) was used to monitor the transitions from precursor ion to product ion for each compound (Supplementary Table 5). Compounds were quantified using external standard curves. Analyst Software 1.6 Build 3773 (AB Sciex) was used for data acquisition and processing.

Samples from the $\mathrm{pH}$ dependency experiment were analyzed by LC-MS/MS using an Advance UHPLC system (Bruker) connected to an EVOQ Elite TripleQuad mass spectrometer (Bruker) equipped with an electrospray ion source. 
Separation was achieved on a Kinetex $1.7 \mathrm{u}$ XB-C18 column $(100 \mathrm{~mm} \times 2.1 \mathrm{~mm}$, $1.7 \mu \mathrm{m}, 100 \AA$ , Phenomenex) using a binary solvent system consisting of $0.05 \%$ (v/ v) formic acid in water (A) and acetonitrile with $0.05 \%(\mathrm{v} / \mathrm{v})$ formic acid (B), with a flow rate of $0.4 \mathrm{~mL} / \mathrm{min}$ at $40{ }^{\circ} \mathrm{C}$. The elution gradient was as follows: $0-0.2 \mathrm{~min}$, $2 \%$ B; $0.2-1.8$ min, $2-30 \%$ B; $1.8-2.5$ min, $30-100 \%$ B; $2.5-2.8$ min, $100 \%$ B $2.8-2.9 \mathrm{~min}, 100$ to $2 \% \mathrm{~B}$; and $2.9-4.0 \mathrm{~min}, 2 \% \mathrm{~B}$. Glucosinolates were detected in negative ionization mode. The instrument parameters were optimized by infusion experiments with pure standards. The ion spray voltage was set to $-4000 \mathrm{~V}$. Cone temperature was set to $350^{\circ} \mathrm{C}$, cone gas to $20 \mathrm{psi}$, heated probe temperature to $200^{\circ}$ $\mathrm{C}$, and probe gas flow to $50 \mathrm{psi}$. Nebulizing gas was set to $60 \mathrm{psi}$, and collision gas to 1.6 mTorr. MRM parameters are provided in Supplementary Table 5. Bruker MS Workstation software (Version 8.2.1, Bruker) was used for data acquisition and processing of glucosinolates. All other samples from experiments using the oocyte expression system were analyzed using the LC-MS/MS method described above for insect cell-based assays. The concentrations of all glucosinolates in the substrate preference assay were determined using external standard curves. Assays performed to characterize I3M glucosinolate transport were quantified using 2propenyl glucosinolate as an internal standard.

\section{Double-stranded RNA synthesis. We synthesized seven different double-} stranded RNAs (dsRNAs) between 120 and 298 bp in length, one specific for each $\mathrm{PaGTR} 1 / 2 / 3 / 5 / 6 / 7 / 8$, respectively, and a 223-bp fragment of the inducible metalloproteinase inhibitor (IMPI) from the greater wax moth Galleria mellonella (AY330624.1) (dsIMPI) using the T7 RiboMAX ${ }^{\mathrm{m}}$ Express RNAi System (Promega). In silico off-target prediction was done by searches of all possible 21 mers of both RNA strands against the local $P$. armoraciae transcriptome database allowing for two mismatches. Except for PaGTR5, the prediction did not find any off-target towards putative transporter genes in the transcriptome (Supplementary Data 5).

Function of PaGTR1 in vivo. To analyze the function of $P a G T R 1$, we injected newly emerged adult $P$. armoraciae beetles (reared on B. juncea) with $100 \mathrm{~nL}$ ultrapure water containing $80 \mathrm{ng}$ of $d s P a G T R 1$ or $80 \mathrm{ng}$ of $d s I M P I$, respectively, using a Nanoliter 2010 Injector (World Precision Instruments). Injected beetles were provided with detached leaves of 3-4-week-old $B$. juncea plants and kept in plastic containers with moistened tissue in the laboratory under ambient conditions. Four days after dsRNA injection, we collected $d s I M P I-$ and $d s P a G T R 1-$ injected beetles for gene expression analysis ( $n=5$ replicates, three beetles per replicate) and glucosinolate analysis ( $n=10$ replicates, three beetles per replicate), respectively. The remaining beetles were used for a sequestration experiment with Arabidopsis thaliana Col-0 (Arabidopsis) plants that had been cultivated in a growth chamber at $21{ }^{\circ} \mathrm{C}, 55 \%$ relative humidity, and a 10 -h photoperiod. To compare the accumulation and excretion of ingested glucosinolates in dsIMPI- and dsPaGTR1-injected beetles, we fed beetles with detached Arabidopsis leaves in Petri dishes $(60 \mathrm{~mm}$ diameter) that contained $50 \mu \mathrm{L}$ of ultrapure water and were sealed with parafilm to prevent leaf wilting ( $n=10$ replicates, five beetles per replicate). Feeding assays were performed in the laboratory under ambient conditions, and leaves were exchanged every day for five consecutive days. To estimate how much the beetles fed, we determined the weight of each leaf before and after feeding. Feces were collected every day using $100 \mu \mathrm{L}$ of ultrapure water per replicate, combined with $300 \mu \mathrm{L}$ of pure methanol in a $1.5 \mathrm{~mL}$ Eppendorf tube and dried by vacuum centrifugation. Feces samples were then homogenized in $200 \mu \mathrm{L}$ of $80 \%$ (v/ v) methanol using metal beads (2.4 $\mathrm{mm}$ diameter, Askubal) in a tissue lyzer (Qiagen) for $1 \mathrm{~min}$ at $30 \mathrm{~Hz}$. After feeding, adults were starved for one day, weighed, frozen in liquid nitrogen, and stored at $-20^{\circ} \mathrm{C}$ until glucosinolate extraction. Beetle samples were homogenized using a plastic pestle in $200 \mu \mathrm{L} 80 \%$ $(\mathrm{v} / \mathrm{v})$ methanol. All samples were then extracted with $1 \mathrm{~mL} 80 \%(\mathrm{v} / \mathrm{v})$ methanol containing $25 \mu \mathrm{M}$ 4-hydroxybenzyl glucosinolate as an internal standard. After centrifugation $(16,000 \times g$ for $10 \mathrm{~min})$, glucosinolates were extracted from the supernatant, converted to desulfo-glucosinolates, and analyzed by highperformance liquid chromatography coupled with diode array detection (HPLCDAD) as described below. The glucosinolate content in adults or feces was calculated in nanomole per adult, respectively.

To confirm the specificity of PaGTR1 knockdown, we analyzed the effect of dsPaGTR1 injection on the expression of PaGTR2, PaGTR3, PaGTR9, and PaGTR10. PaGTR9 and PaGTR10 share the highest nucleotide sequence similarity (69\% sequence identity) with PaGTR1. PaGTR2 and PaGTR3 expression was analyzed because the recombinant transporters also used I3M glucosinolate as a substrate. RNA extraction, purification, $\mathrm{cDNA}$ synthesis, and $\mathrm{qPCR}$ were performed as described above.

Function of PaGTR5/6/7/8 in vivo. To analyze the function of $P a G T R 5 / 6 / 7 / 8$, we injected newly emerged adult $P$. armoraciae beetles that had fed for 2 days on $B$. juncea leaves with $100 \mathrm{~nL}$ ultrapure water containing $100 \mathrm{ng}$ of $d$ SIMPI or each 100 ng of $d s P a G T R 5 / 6 / 7 / 8$ using a Nanoliter 2010 Injector (World Precision Instruments). A subset of the dsRNA-injected beetles was fed with detached leaves of Arabidopsis plants in plastic containers with moistened tissue for gene expression analysis ( $n=6$ replicates, two beetles per replicate). The remaining dsRNA-injected beetles were used for a sequestration experiment with Arabidopsis plants to compare the accumulation and excretion of previously stored and ingested glucosinolates in $d s I M P I-$ and $d s P a G T R 5 / 6 / 7 / 8$-injected beetles. We fed the injected beetles with detached Arabidopsis leaves in Petri dishes $(60 \mathrm{~mm}$ diameter that contained $30 \mu \mathrm{L}$ of ultrapure water and were sealed with parafilm to prevent leaf wilting ( $n=10$ replicates, six beetles per replicate). Feeding assays were performed in the laboratory under ambient conditions, and leaves were exchanged every day for six consecutive days. To estimate how much the beetles fed, we determined the weight of each leaf before and after feeding. Starting from the second day, feces were collected as above for 5 days. After drying by vacuum centrifugation, feces were homogenized in $1 \mathrm{~mL}$ of $80 \%(\mathrm{v} / \mathrm{v})$ methanol containing $25 \mu \mathrm{M}$ 4-hydroxybenzyl glucosinolate as an internal standard using metal beads (2.4 mm diameter, Askubal) in a tissue lyzer (Qiagen) for $1 \mathrm{~min}$ at $30 \mathrm{~Hz}$. Fed adults were starved for 1 day, weighed, and frozen in liquid nitrogen until glucosinolate extraction. Beetle samples were homogenized using a plastic pestle in 200 $\mu \mathrm{L}$ of $80 \%(\mathrm{v} / \mathrm{v})$ methanol and then extracted with $1 \mathrm{~mL}$ of $80 \%(\mathrm{v} / \mathrm{v})$ methanol containing $25 \mu \mathrm{M}$ 4-hydroxybenzyl glucosinolate as an internal standard. After centrifugation $(16,000 \times g$ for $10 \mathrm{~min})$, glucosinolates were extracted from the supernatant, converted to desulfo-glucosinolates, and analyzed by HPLC-DAD as described below.

To confirm the specificity of PaGTR5/6/7/8 knockdown, we analyzed the effect of $d s P a G T R 5 / 6 / 7 / 8$ injection on the expression of PaGTR 9 and PaGTR10, which share the highest nucleotide sequence similarity (67-69\% sequence identity) with PaGTR5/6/7/8. RNA extraction, purification, cDNA synthesis, and qPCR were performed as described above.

Function of PaGTR2/3 in vivo. To analyze the functions of $P a G T R 2$ and PaGTR3, we injected third instar larvae of P. armoraciae (reared on B. rapa) with $100 \mathrm{~nL}$ ultrapure water containing $80 \mathrm{ng}$ of $d s P a G T R 2$ and $80 \mathrm{ng}$ of $d s P a G T R 3$ (dsPaGTR2/ 3) or $80 \mathrm{ng}$ of $d s I M P I$, respectively, using a Nanoliter 2010 Injector (World Precision Instruments). Injected larvae were provided with detached B. rapa petioles and kept in plastic tubes with moistened tissue in the laboratory under ambient conditions until pupation. Newly emerged adults were again injected with dsRNAs and provided with detached $B$. rapa leaves. Three days after the second dsRNA injection, we collected $d s I M P I-$ and $d s P a G T R 2 / 3$-injected beetles for gene expression analysis ( $n=6$ replicates, two beetles per replicate) and glucosinolate analysis ( $n=10$ replicates, three beetles per replicate), respectively. The remaining beetles were used for a feeding experiment with Arabidopsis. Each replicate consisted of one Arabidopsis leaf and three beetles that were placed in a Petri dish $(60 \mathrm{~mm}$ diameter) with $50 \mu \mathrm{L}$ of ultrapure water $(n=12-13$ replicates). Each leaf was photographed before and after feeding to determine the consumed leaf area. Fed leaves were frozen in liquid nitrogen, freeze-dried, and homogenized using metal beads ( $2.4 \mathrm{~mm}$ diameter, Askubal) in a tissue lyzer (Qiagen) for $2 \mathrm{~min}$ at $30 \mathrm{~Hz}$. Fed beetles were starved for 1 day, weighed, frozen in liquid nitrogen, and stored at $-20^{\circ} \mathrm{C}$ until glucosinolate extraction. Beetle samples were homogenized using a plastic pestle in $200 \mu \mathrm{L} 80 \%(\mathrm{v} / \mathrm{v})$ methanol. All samples were extracted with $1 \mathrm{~mL}$ $80 \%(\mathrm{v} / \mathrm{v})$ methanol containing $25 \mu \mathrm{M}$ 1-methylethyl glucosinolate (extracted from Sisymbrium officinale seeds) as an internal standard. Extracts were applied to DEAE-Sephadex A-25 (Sigma-Aldrich) columns in 96-well filter plates (Nunc) that were preconditioned with $1 \mathrm{~mL}$ of ultrapure water and $2 \times 500 \mu \mathrm{L}$ of $80 \%(\mathrm{v} / \mathrm{v})$ methanol. After loading $900 \mu \mathrm{L}$ of extract, the columns were washed with $500 \mu \mathrm{L}$ of $80 \%(\mathrm{v} / \mathrm{v})$ methanol, followed by $2 \times 1 \mathrm{~mL}$ of ultrapure water. To adjust the $\mathrm{pH}$ condition, $500 \mu \mathrm{L}$ of $0.02 \mathrm{M}$ MES buffer ( $\mathrm{pH}$ 5.2) was added to each column After adding $30 \mu \mathrm{L}$ of Helix pomatia sulfatase solution to each column and overnight incubation at room temperature, desulfo-glucosinolates were eluted using 300 or $500 \mu \mathrm{L}$ of ultrapure water into 96-deep well plates (Nunc). Samples were analyzed by desulfo-HPLC-DAD as described below. The glucosinolate content in adults and fed leaves was calculated in nanomole per adult and nanomole per $\mathrm{cm}^{2}$ leaf, respectively. The ingested glucosinolate amount was calculated based on the ingested leaf area and the corresponding leaf glucosinolate content. To elucidate which proportion of the ingested glucosinolates was sequestered, we expressed the glucosinolate amount detected in the beetles relative to the ingested glucosinolate amount from the leaves, which was set to $100 \%$.

HPLC-DAD. Samples were analyzed by HPLC on an Agilent Technologies HP1100 Series instrument equipped with a photodiode array detector. After injection of $100 \mu \mathrm{L}$ of each sample, separation was achieved on an EC 250/4.6 NUCLEODUR Sphinx RP column $(250 \mathrm{~mm} \times 4.6 \mathrm{~mm}, 5 \mu \mathrm{m}$; Macherey-Nagel; samples of the RNA interference (RNAi) experiments of PaGTR1, and PaGTR2/3) or an EC 250/4.6 NUCLEODUR 100-5 C18ec column $(250 \mathrm{~mm} \times 4.6 \mathrm{~mm}, 5 \mu \mathrm{m}$; MachereyNagel; samples of the RNAi experiments of $P a G T R 5 / 6 / 7 / 8$, and $P a G T R 2 / 3)$ using a binary solvent system consisting of ultrapure water (A) and acetonitrile (B), with a flow rate of $1 \mathrm{~mL} / \mathrm{min}$. The elution gradient was as follows: $0-1 \mathrm{~min}, 1.5 \% \mathrm{~B} ; 1-6$ $\min , 1.5-5 \% \mathrm{~B} ; 6-8 \mathrm{~min}, 5-7 \% \mathrm{~B} ; 8-18 \min , 7-21 \% \mathrm{~B} ; 18-23 \mathrm{~min}, 21-29 \% \mathrm{~B}$; $23-23.5 \mathrm{~min}, 29-100 \% \mathrm{~B} ; 23.5-26 \mathrm{~min}, 100 \% \mathrm{~B} ; 26-26.1 \mathrm{~min}, 100$ to $1.5 \% \mathrm{~B}$; and 26.1-31 $\mathrm{min}, 1.5 \% \mathrm{~B}$. The eluent was monitored by diode array detection between 190 and $360 \mathrm{~nm}$. Desulfo-glucosinolates were identified based on a comparison of retention times and absorption spectra with those of known standards ${ }^{63}$. The glucosinolate content in each sample was calculated from the peak areas at $229 \mathrm{~nm}$ relative to the peak area of the internal standard using relative response factors ${ }^{64}$ 


\section{Glucosinolate concentration in the hemolymph of adult $\boldsymbol{P}$. armoraciae}

Hemolymph was collected from 7-day-old adult $P$. armoraciae reared on $B$. juncea by cutting off an abdominal leg and collecting the extruding droplet using glass capillaries $\left(0.5 \mu \mathrm{L}\right.$, Hirschmann ${ }^{\oplus}$ minicaps $\left.{ }^{\circ}\right)(n=6$ replicates, 50 beetles per replicate). The capillaries were marked with $1 \mathrm{~mm}$ intervals (corresponding to $15.6 \mathrm{~nL}$ ) to estimate the volume of collected hemolymph. The hemolymph was diluted in $500 \mu \mathrm{L}$ of $90 \%(\mathrm{v} / \mathrm{v})$ methanol, homogenized using metal beads $(2.4 \mathrm{~mm}$ diameter, Askubal) in a tissue lyzer (Qiagen) for $1 \mathrm{~min}$ at $30 \mathrm{~Hz}$, and boiled for 5 $\mathrm{min}$ at $95^{\circ} \mathrm{C}$. After two centrifugation steps $(13,000 \times \mathrm{g}$ for $10 \mathrm{~min}$ each), the supernatant was dried by vacuum centrifugation, dissolved in $50 \mu \mathrm{L} 50 \%(\mathrm{v} / \mathrm{v})$ methanol, diluted in ultrapure water, and analyzed by LC-MS/MS

Morphology of the Malpighian tubule system of $\boldsymbol{P}$. armoraciae. To investigate the structure of the Malpighian tubule system, we dissected the gut and Malpighian tubules of 4-day-old P. armoraciae adults in PBS ( $\mathrm{pH}$ 6.0) under a stereomicroscope. The tracheae that attach Malpighian tubules to the gut were removed using fine forceps to release the tubules. Pictures were taken with a Canon EOS 600D camera.

\section{pH of hemolymph and excretion fluid of isolated Malpighian tubules of $P$.} armoraciae. The $\mathrm{pH}$ of the hemolymph and Malpighian tubule excretion fluid of 5-day-old $P$. armoraciae adults was assessed using the $\mathrm{pH}$ indicator bromothymol blue (Alfa Aesar). Hemolymph was collected by cutting off an abdominal leg and collecting the extruding droplet using a pipette $(n=3$ replicates, six to ten beetles per replicate). Excretion fluid was collected from dissected Malpighian tubules that were incubated in saline $\mathrm{A}$ as described for the Ramsay assay $(n=4$ replicates, one tubule per replicate). Hemolymph and excretion fluid were immediately mixed with the same volume of $0.16 \%(\mathrm{w} / \mathrm{v})$ bromothymol blue dissolved in $10 \%(\mathrm{v} / \mathrm{v})$ ethanol, respectively, under water-saturated paraffin oil in a Sylgard-coated petri dish. The resulting color of the droplet was compared with those of citric acid- $\mathrm{Na}_{2} \mathrm{HPO}_{4}$ buffer solutions ranging from $\mathrm{pH} 5.2$ to 6.6 in 0.2 increments mixed with $0.16 \%(\mathrm{w} / \mathrm{v})$ bromothymol blue.

Fate of plant glucosides injected in P. armoraciae beetles. To analyze the fate of plant glucosides in vivo, we injected $100 \mathrm{~nL}$ of an equimolar mixture of 2-propenyl glucosinolate, 4-hydroxybenzyl glucosinolate, linamarin, salicin, and catalpol, each at $10 \mathrm{mM}$, and $0.15 \%(\mathrm{w} / \mathrm{v})$ amaranth into the hemolymph of 2-day-old adult P. armoraciae (reared on B. rapa). One group of beetles was sampled $30 \mathrm{~min}$ after injection by freezing beetles in liquid nitrogen $(n=10$ replicates, five beetles per replicate). The remaining beetles were fed with detached leaves of Arabidopsis in Petri dishes $(60 \mathrm{~mm}$ diameter) in the laboratory under ambient conditions $(n=10$ replicates, five beetles per replicate). We added $30 \mu \mathrm{L}$ of ultrapure water to each Petri dish and sealed them with parafilm to prevent leaf wilting. After 1 day, we sampled the beetles as described above ( $n=10$ replicates, five beetles per replicate). Feces were collected using $100 \mu \mathrm{L}$ of ultrapure water per replicate and combined with $300 \mu \mathrm{L}$ of pure methanol in a $1.5 \mathrm{~mL}$ Eppendorf tube. All samples were stored at $-20{ }^{\circ} \mathrm{C}$ until extraction. Beetle and feces samples were homogenized as described in the RNAi experiment. After centrifugation $(16,000 \times g$ for $10 \mathrm{~min})$, the supernatant was dried by vacuum centrifugation, dissolved in $100 \mu \mathrm{L}$ of ultrapure water, and analyzed by LC-MS/MS. The glucoside content in adults or feces was calculated as nanomole per adult, respectively.

Ramsay assay. To analyze the excretion of plant glucosides in situ, we performed Ramsay assays ${ }^{65}$ with dissected Malpighian tubules from 4- to 5-day-old $P$. armoraciae adults reared on $\mathrm{B}$. rapa (Supplementary Fig. 6). Malpighian tubules were dissected in saline A $\left(100 \mathrm{mM} \mathrm{NaCl}, 8.6 \mathrm{mM} \mathrm{KCl}, 2 \mathrm{mM} \mathrm{CaCl}_{2}, 8.5 \mathrm{mM}\right.$ $\mathrm{MgCl}_{2}, 4 \mathrm{mM} \mathrm{NaH} \mathrm{PO}_{4}, 4 \mathrm{mM} \mathrm{NaHCO}_{3}, 24 \mathrm{mM}$ glucose, $10 \mathrm{mM}$ proline, $25 \mathrm{mM}$ 3 -( $N$-morpholino)propanesulfonic acid (MOPS), $\mathrm{pH}$ 6.0) ${ }^{66}$. Single tubules were transferred into a $10 \mu \mathrm{L}$ droplet of saline B $(60 \mathrm{mM} \mathrm{NaCl}, 10.3 \mathrm{mM} \mathrm{KCl}, 2.4 \mathrm{mM}$ $\mathrm{CaCl}_{2}, 10.2 \mathrm{mM} \mathrm{MgCl}_{2}, 4.8 \mathrm{mM} \mathrm{NaH}_{2} \mathrm{PO}_{4}, 4.8 \mathrm{mM} \mathrm{NaHCO}_{3}, 28.8 \mathrm{mM}$ glucose, 12 $\mathrm{mM}$ proline, $30 \mathrm{mM}$ MOPS, $1 \mathrm{mM}$ cyclic AMP, $\mathrm{pH}$ 6.0) under water-saturated paraffin oil in a Sylgard-coated petri dish. The proximal end of the tubule was pulled out of the droplet, attached to a metal pin, and cut using a glass capillary to allow the collection of excretion fluid. To start the assay, we added $2 \mu \mathrm{L}$ of an equimolar glucoside mixture consisting of 2-propenyl glucosinolate, 4methylsulfinylbutyl glucosinolate, 4-hydroxybenzyl glucosinolate, 2-phenylethyl glucosinolate, I3M glucosinolate, linamarin, salicin, and catalpol, each at $40 \mathrm{mM}$, and $0.6 \%(\mathrm{w} / \mathrm{v})$ amaranth) to saline B. After $2-3 \mathrm{~h}$, we collected the excretion fluid and $2 \mu \mathrm{L}$ of the bathing droplet in $300 \mu \mathrm{L}$ of $80 \%(\mathrm{v} / \mathrm{v})$ methanol, respectively. The Malpighian tubule was washed three times in $\sim 15 \mathrm{~mL}$ of saline A and afterwards transferred into $300 \mu \mathrm{L}$ of $80 \%(\mathrm{v} / \mathrm{v})$ methanol. All samples were stored at $-20^{\circ} \mathrm{C}$ until extraction. Malpighian tubule samples were homogenized using a plastic pestle. After centrifugation $(16,000 \times g$ for $10 \mathrm{~min})$, the supernatant was dried by vacuum centrifugation, dissolved in $70 \mu \mathrm{L}$ ultrapure water, and analyzed by LCMS/MS. Out of 36 assays, 25 assays were excluded because no excretion fluid was visible within $2-3 \mathrm{~h}$.

Statistical analysis. No statistical methods were used to predetermine sample size. Statistical analyses were conducted in R 3.5.167 or in SigmaPlot 14.0 or 14.5 (Systat
Software Inc.). Two groups were compared by two-tailed Student's $t$ test, Mann-Whitney $U$ test, or the method of generalized least squares ${ }^{68}$, depending on the variance homogeneity and the normality of residuals. Data of the Ramsay assays were compared by paired two-tailed Student's $t$ test using FDR (false discovery rate)-corrected $P$ values ${ }^{69}$. Three or more groups were compared by oneway analysis of variance, followed by post hoc multiple comparisons test, or the method of generalized least squares ${ }^{68}$. If necessary, data were transformed prior to analysis. For comparisons using the method of generalized least squares, we applied the varIdent variance structure, which allows each group to have a different variance. The $P$ value was obtained by comparing models with and without explanatory variables using a likelihood ratio test ${ }^{70}$. Significant differences between groups were revealed with factor level reductions ${ }^{71}$. Information about data transformation, statistical methods, and results of the statistical analyses are summarized in Supplementary Tables 2 and 3 and Supplementary Data 6.

Reporting summary. Further information on research design is available in the Nature Research Reporting Summary linked to this article.

\section{Data availability}

The data that support the findings of this study are available from the corresponding author upon request. The sequences of the genes cloned in this paper have been deposited in the GenBank database (accession numbers MN433061-MN433082). Raw RNAseq datasets of Phyllotreta armoraciae are deposited in the sequence read archive (SRA) database (accession number PRJNA716471). The predicted protein datasets of Leptinotarsa decemlineata and Anoplophora glabripennis genome was retrieved from publicly available database [ftp://ftp.hgsc.bcm.edu/I5K-pilot/Colorado_Potato_Beetle/ maker_annotation/version_0.5.3/LDEC.faa] and [https://ftp.ncbi.nlm.nih.gov/genomes/ all/GCF/000/390/285/GCF_000390285.1_Agla_1.0/GCF_000390285.1_Agla_1.0_protein. faa.gz], respectively. The predicted protein dataset of Tribolium castaneum based on the previous assembly version Tcas 3.0 used for the annotation of putative transporters is provided as Supplementary Data 7. Source data are provided with this paper.

Received: 15 November 2020; Accepted: 6 April 2021; Published online: 11 May 2021

\section{References}

1. Simon, J.-C. et al. Genomics of adaptation to host-plants in herbivorous insects. Brief. Funct. Genomics 14, 413-423 (2015).

2. Ali, J. G. \& Agrawal, A. A. Specialist versus generalist insect herbivores and plant defense. Trends Plant Sci. 17, 293-302 (2012).

3. Edger, P. P. et al. The butterfly plant arms-race escalated by gene and genome duplications. Proc. Natl Acad. Sci. USA 112, 8362-8366 (2015).

4. Gouin, A. et al. Two genomes of highly polyphagous lepidopteran pests (Spodoptera frugiperda, Noctuidae) with different host-plant ranges. Sci. Rep. 7, 1-12 (2017).

5. Heckel, D. G. In Annual Plant Reviews: Insect-Plant Interactions (eds. Voelckel, C. \& Jander, G.), Ch. 3, 77-114 (Wiley, 2014).

6. Petschenka, G. \& Agrawal, A. A. How herbivores coopt plant defenses: natural selection, specialization, and sequestration. Curr. Opin. Insect Sci. 14, 17-24 (2016).

7. Zvereva, E. L. \& Kozlov, M. V. The costs and effectiveness of chemical defenses in herbivorous insects: a meta-analysis. Ecol. Monogr. 86, 107-124 (2016).

8. Bernays, E. \& Graham, M. On the evolution of host specificity in phytophagous arthropods. Ecology 69, 886-892 (1988).

9. Robert, C. A. et al. Sequestration and activation of plant toxins protect the western corn rootworm from enemies at multiple trophic levels. eLife $\mathbf{6}$, e29307 (2017)

10. Petschenka, G. \& Agrawal, A. A. Milkweed butterfly resistance to plant toxins is linked to sequestration, not coping with a toxic diet. Proc. Biol. Sci. 282, 20151865 (2015).

11. Opitz, S. E. W. \& Müller, C. Plant chemistry and insect sequestration. Chemoecology 19, 117-154 (2009).

12. Jeschke, V. \& Burow, M. Glucosinolates. eLS (Wiley, Chichester, 2018).

13. Blažević, I. et al. Glucosinolate structural diversity, identification, chemical synthesis and metabolism in plants. Phytochemistry 169, 112100 (2019).

14. Kissen, R., Rossiter, J. T. \& Bones, A. M. The 'mustard oil bomb': not so easy to assemble?! Localization, expression and distribution of the components of the myrosinase enzyme system. Phytochem. Rev. 8, 69-86 (2009).

15. Wittstock, U., Kurzbach, E., Herfurth, A.-M. \& Stauber, E. J. Glucosinolate Breakdown. Glucosinolates, Ch. 6 (Elsevier, 2016).

16. Jeschke, V., Gershenzon, J. \& Vassão, D. G. A mode of action of glucosinolatederived isothiocyanates: detoxification depletes glutathione and cysteine levels with ramifications on protein metabolism in Spodoptera littoralis. Insect Biochem. Mol. Biol. 71, 37-48 (2016). 
17. Burow, M., Müller, R., Gershenzon, J. \& Wittstock, U. Altered glucosinolate hydrolysis in genetically engineered Arabidopsis thaliana and its influence on the larval development of Spodoptera littoralis. J. Chem. Ecol. 32, 2333-2349 (2006).

18. Li, Q., Eigenbrode, S. D., Stringam, G. \& Thiagarajah, M. Feeding and growth of Plutella xylostella and Spodoptera eridania on Brassica juncea with varying glucosinolate concentrations and myrosinase activities. J. Chem. Ecol. 26, 2401-2419 (2000).

19. Falk, K. L. et al. The role of glucosinolates and the jasmonic acid pathway in resistance of Arabidopsis thaliana against molluscan herbivores. Mol. Ecol. 23, 1188-1203 (2014).

20. Müller, C. et al. Sequestration of host plant glucosinolates in the defensive hemolymph of the sawfly Athalia rosae. J. Chem. Ecol. 27, 2505-2516 (2001).

21. Kazana, E. et al. The cabbage aphid: a walking mustard oil bomb. Proc. Biol. Sci. 274, 2271-2277 (2007).

22. Aliabadi, A., Renwick, J. A. A. \& Whitman, D. W. Sequestration of glucosinolates by harlequin bug Murgantia histrionica. J. Chem. Ecol. 28, 1749-1762 (2002).

23. Beran, F. et al. Phyllotreta striolata flea beetles use host plant defense compounds to create their own glucosinolate-myrosinase system. Proc. Natl Acad. Sci. USA 111, 7349-7354 (2014).

24. Beran, F. et al. One pathway is not enough: the cabbage stem flea beetle Psylliodes chrysocephala uses multiple strategies to overcome the glucosinolate-myrosinase defense in its host plants. Front. Plant Sci. 9, 1754 (2018).

25. Yang, Z.-L., Kunert, G., Sporer, T., Körnig, J. \& Beran, F. Glucosinolate abundance and composition in Brassicaceae influence sequestration in a specialist flea beetle. J. Chem. Ecol. 46, 186-197 (2020).

26. Sporer, T., Körnig, J. \& Beran, F. Ontogenetic differences in the chemical defence of flea beetles influence their predation risk. Funct. Ecol. 34, 1370-1379 (2020).

27. Müller, C. \& Wittstock, U. Uptake and turn-over of glucosinolates sequestered in the sawfly Athalia rosae. Insect Biochem. Mol. Biol. 35, 1189-1198 (2005).

28. van Geem, M., Harvey, J. A. \& Gols, R. Development of a generalist predator, Podisus maculiventris, on glucosinolate sequestering and nonsequestering prey. Naturwissenschaften 101, 707-714 (2014).

29. Abdalsamee, M. K., Giampà, M., Niehaus, K. \& Müller, C. Rapid incorporation of glucosinolates as a strategy used by a herbivore to prevent activation by myrosinases. Insect Biochem. Mol. Biol. 52, 115-123 (2014).

30. Strauss, A. S., Peters, S., Boland, W. \& Burse, A. ABC transporter functions as a pacemaker for sequestration of plant glucosides in leaf beetles. eLife $\mathbf{2}$, e01096 (2013).

31. Kowalski, P., Baum, M., Körten, M., Donath, A. \& Dobler, S. ABCB transporters in a leaf beetle respond to sequestered plant toxins. Proc. R. Soc. Ser. B 287, 20201311 (2020).

32. Nielsen, J. K. Host plant-selection of monophagous and oligophagous flea beetles feeding on crucifers. Entomol. Exp. Appl. 24, 562-569 (1978).

33. Nielsen, J. K., Dalgaard, L., Larsen, L. M. \& Sørensen, H. Host plant selection of the horse-radish flea beetle Phyllotreta armoraciae (Coleoptera: Chrysomelidae): feeding responses to glucosinolates from several crucifers. Entomol. Exp. Appl. 25, 227-239 (1979).

34. Vig, K. \& Verdyck, P. Data on the host plant selection of the horseradish flea beetle, Phyllotreta armoraciae (Koch, 1803) (Coleoptera, Chrysomelidae, Alticinae). Mededelingen van. de. Faculteit Landbouwwetenschappen Univsiteit Gent 66, 277-283 (2001)

35. Elbourne, L. D., Tetu, S. G., Hassan, K. A. \& Paulsen, I. T. TransportDB 2.0: a database for exploring membrane transporters in sequenced genomes from all domains of life. Nucleic Acids Res. 45, D320-D324 (2017).

36. Law, C. J., Maloney, P. C. \& Wang, D. N. Ins and outs of major facilitator superfamily antiporters. Annu. Rev. Microbiol. 62, 289-305 (2008).

37. Quistgaard, E. M., Low, C., Guettou, F. \& Nordlund, P. Understanding transport by the major facilitator superfamily (MFS): structures pave the way. Nat. Rev. Mol. Cell Biol. 17, 123-132 (2016).

38. Meredith, J., Moore, L. \& Scudder, G. Excretion of ouabain by Malpighian tubules of Oncopeltus fasciatus. Am. J. Physiol. 246, R705-R715 (1984).

39. O'Donnell, M. Too much of a good thing: how insects cope with excess ions or toxins in the diet. J. Exp. Biol. 212, 363-372 (2009).

40. Chapman, R. F. In The Insects: Structure and Function Part 3 (eds. Simpson, S. J. \& Angela, E. D.) (Cambridge Univ. Press, 2013).

41. Kikawada, T. et al. Trehalose transporter 1, a facilitated and high-capacity trehalose transporter, allows exogenous trehalose uptake into cells. Proc. Natl Acad. Sci. USA 104, 11585-11590 (2007).

42. Kikuta, S., Hagiwara-Komoda, Y., Noda, H. \& Kikawada, T. A novel member of the trehalose transporter family functions as an $\mathrm{H}^{+}$-dependent trehalose transporter in the reabsorption of trehalose in Malpighian tubules. Front. Physiol. 3, 290 (2012).
43. Price, D. R. \& Gatehouse, J. A. Genome-wide annotation and functional identification of aphid GLUT-like sugar transporters. BMC Genomics 15, 647 (2014).

44. Nour-Eldin, H. H. et al. NRT/PTR transporters are essential for translocation of glucosinolate defence compounds to seeds. Nature 488, 531-534 (2012).

45. Jørgensen, M. E. et al. Origin and evolution of transporter substrate specificity within the NPF family. eLife 6, e19466 (2017).

46. Wang, C. et al. Iridoids: research advances in their phytochemistry, biological activities, and pharmacokinetics. Molecules 25, 287 (2020).

47. Dobler, S., Petschenka, G. \& Pankoke, H. Coping with toxic plant compounds-the insect's perspective on iridoid glycosides and cardenolides. Phytochemistry 72, 1593-1604 (2011).

48. Willinger, G. \& Dobler, S. Selective sequestration of iridoid glycosides from their host plants in Longitarsus flea beetles. Biochem. Syst. Ecol. 29, 335-346 (2001).

49. Nie, R.-E. et al. The phylogeny of leaf beetles (Chrysomelidae) inferred from mitochondrial genomes. Syst. Entomol. 45, 188-204 (2020).

50. Opitz, S. E. et al. Host shifts from Lamiales to Brassicaceae in the sawfly genus Athalia. PLoS ONE 7, e33649 (2012).

51. Nishida, R. Sequestration of defensive substances from plants by Lepidoptera Annu. Rev. Entomol. 47, 57-92 (2002).

52. Schmidt, L., Wielsch, N., Wang, D., Boland, W. \& Burse, A. Tissue-specific profiling of membrane proteins in the salicin sequestering juveniles of the herbivorous leaf beetle, Chrysomela populi. Insect Biochem. Mol. Biol. 109 81-91 (2019).

53. Saier, M. H. Jr. et al. The Transporter Classification Database (TCDB): recent advances. Nucleic Acids Res. 44, D372-D379 (2016).

54. Krogh, A., Larsson, B., Von Heijne, G. \& Sonnhammer, E. L. Predicting transmembrane protein topology with a hidden Markov model: application to complete genomes. J. Mol. Biol. 305, 567-580 (2001).

55. Schoville, S. D. et al. A model species for agricultural pest genomics: the genome of the Colorado potato beetle, Leptinotarsa decemlineata (Coleoptera: Chrysomelidae). Sci. Rep. 8, 1931 (2018).

56. McKenna, D. D. et al. Genome of the Asian longhorned beetle (Anoplophora glabripennis), a globally significant invasive species, reveals key functional and evolutionary innovations at the beetle-plant interface. Genome Biol. 17, 227 (2016).

57. Richards, S. et al. The genome of the model beetle and pest Tribolium castaneum. Nature 452, 949-955 (2008).

58. Kumar, S., Stecher, G. \& Tamura, K. MEGA7: Molecular evolutionary genetics analysis version 7.0 for bigger datasets. Mol. Biol. Evol. 33, 1870-1874 (2016).

59. Darriba, D., Taboada, G. L., Doallo, R. \& Posada, D. ProtTest 3: fast selection of best-fit models of protein evolution. Bioinformatics 27, 1164-1165 (2011)

60. Nguyen, L. T., Schmidt, H. A., von Haeseler, A. \& Minh, B. Q. IQ-TREE: a fast and effective stochastic algorithm for estimating maximum-likelihood phylogenies. Mol. Biol. Evol. 32, 268-274 (2015).

61. Thies, W. Isolation of sinigrin and glucotropaeolin from cruciferous seeds. Fat Sci. Technol. 90, 311-314 (1988).

62. Kelly, S. M., Butler, J. P. \& Macklem, P. T. Control of cell volume in oocytes and eggs from Xenopus laevis. Comp. Biochem. Phys. A 111, 681-691 (1995)

63. Reichelt, M. et al. Benzoic acid glucosinolate esters and other glucosinolates from Arabidopsis thaliana. Phytochemistry 59, 663-671 (2002).

64. Clarke, D. B. Glucosinolates, structures and analysis in food. Anal. Methods 2 310-325 (2010).

65. Ramsay, J. Excretion by the Malpighian tubules of the stick insect, Dixippus morosus (Orthoptera, Phasmidae): amino acids, sugars and urea. J. Exp. Biol. 35, 871-891 (1958).

66. Browne, A. \& O’Donnell, M. J. Mechanisms of calcium sequestration by isolated Malpighian tubules of the house cricket Acheta domesticus. Arch. Insect Biochem. Physiol. 97, e21431 (2018).

67. R Core Team. R: A Language and Environment for Statistical Computing (R Foundation for Statistical Computing, 2018)

68. Pinheiro, J., Bates, D., DebRoy, S., Sarkar, D. \& R Core Team. Nlme: linear and nonlinear mixed effects models. http://cran.r-project.org/package $=$ nlme (2019).

69. Benjamini, Y. \& Hochberg, Y. Controlling the false discovery rate: a practical and powerful approach to multiple testing. J. R. Stat. Soc. Ser. B 57, 289-300 (1995).

70. Zuur, A. F., Ieno, E. N., Walker, N. J., Saveliev, A. A. \& Smith, G. M. Mixed Effects Models and Extensions in Ecology with $R$ (Springer, 2009).

71. Crawley, M. J. The R Book (Wiley, 2013).

\section{Acknowledgements}

We thank T.G. Köllner, D.G. Heckel, J. Gershenzon, S.E. O’Connor, and M. Burow for comments on the manuscript, S. Donnerhacke, S. Gebauer-Jung, D. Schnabelrauch, 
L. Svenningsen, and A. Schilling for technical help, D. Yang for discussion on the project, and the greenhouse team at the MPI for Chemical Ecology for plant cultivation. This study was funded by the Max Planck Society. Additional support for this work was provided by the Danish National Research Foundation grant DNRF99 (to H.H.N.-E. and C.C.).

\section{Author contributions}

Z.-L.Y. and F.B.: designed the study, conducted data analysis, and wrote the manuscript. F.B. supervised the study. H.H.N.-E. supervised the experiments with oocytes. Z.-L.Y. performed most of the experiments. S.H. contributed to RACE-PCR and gene cloning. M.R. and C.C. contributed to LC-MS/MS and HPLC-DAD analyses. F.B. and H.V. performed transcriptome analysis. F.S. performed the analysis of glucosinolate concentration in hemolymph. All authors commented on the manuscript.

\section{Funding}

Open Access funding enabled and organized by Projekt DEAL.

\section{Competing interests}

The authors declare no competing interests.

\section{Additional information}

Supplementary information The online version contains supplementary material available at https://doi.org/10.1038/s41467-021-22982-8.
Correspondence and requests for materials should be addressed to F.B.

Peer review information Nature Communications thanks Patrick Abbott and Yutao Xiao for their contribution to the peer review of this work.

Reprints and permission information is available at http://www.nature.com/reprints

Publisher's note Springer Nature remains neutral with regard to jurisdictional claims in published maps and institutional affiliations.

(c) (i) Open Access This article is licensed under a Creative Commons Attribution 4.0 International License, which permits use, sharing, adaptation, distribution and reproduction in any medium or format, as long as you give appropriate credit to the original author(s) and the source, provide a link to the Creative Commons license, and indicate if changes were made. The images or other third party material in this article are included in the article's Creative Commons license, unless indicated otherwise in a credit line to the material. If material is not included in the article's Creative Commons license and your intended use is not permitted by statutory regulation or exceeds the permitted use, you will need to obtain permission directly from the copyright holder. To view a copy of this license, visit http://creativecommons.org/ licenses/by/4.0/.

(C) The Author(s) 2021 